\title{
Orthoscuticellines A-E, $\beta$-carboline Alkaloids from the bryozoan Orthoscuticella ventricosa Collected in Australia
}

Guy Kleks, ${ }^{\dagger}$ Sandra Duffy, ${ }^{\S}$ Leonardo Lucantoni, ${ }^{\S}$ Vicky M. Avery, ${ }^{\S}$ and Anthony R. Carroll*†‡

${ }^{\dagger}$ Environmental Futures Research Institute, Griffith University, Gold Coast, QLD 4222, Australia

${ }^{\ddagger}$ Griffith Institute for Drug Discovery, Griffith University, Brisbane, QLD 4111, Australia

${ }^{\S}$ Discovery Biology, Griffith Institute for Drug Discovery, Griffith University, Brisbane, QLD 4111, Australia

\section{Supporting Information}




\section{Table of Figures}

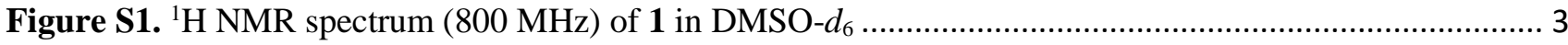

Figure S2. ${ }^{1} \mathrm{H}$ NMR expansion of the cyclobutyl protons of $\mathbf{1}$ (cut out region from 3.10 to $5.00 \mathrm{ppm}$ ) ........... 4

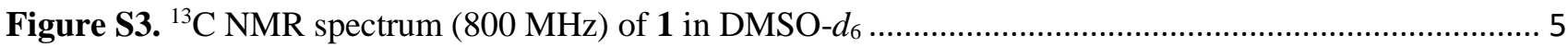

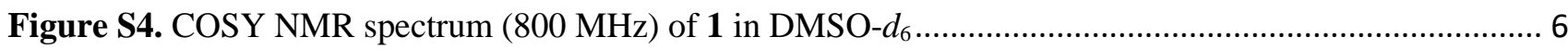

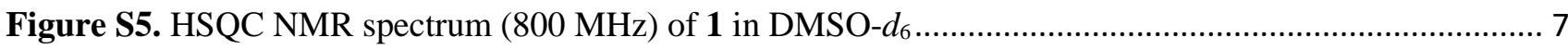

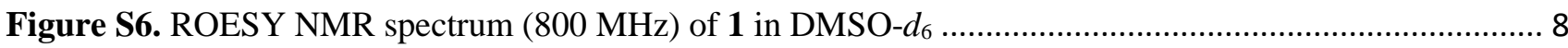

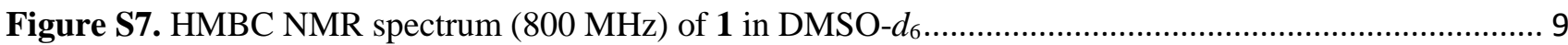

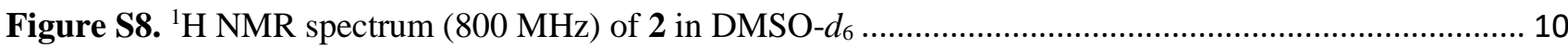

Figure S9. ${ }^{1} \mathrm{H}$ NMR expansion of the cyclobutyl protons of 2 (cut out region from 3.00 to $4.80 \mathrm{ppm}$ ) .......... 11

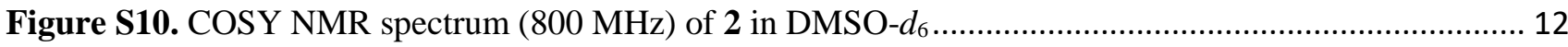

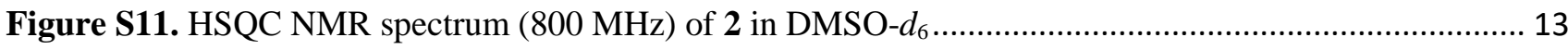

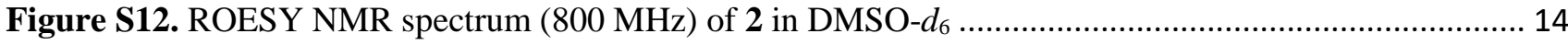

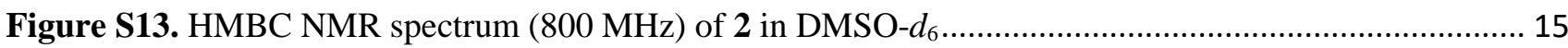

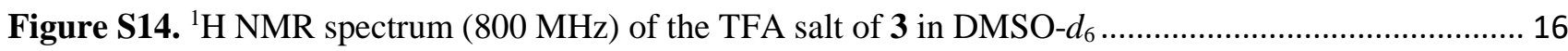

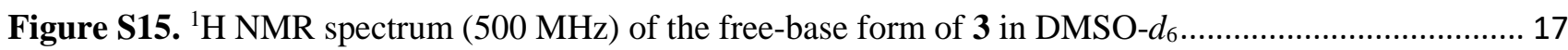

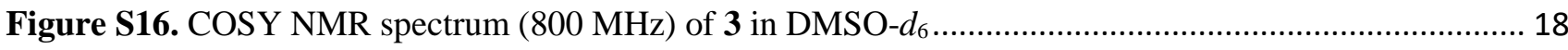

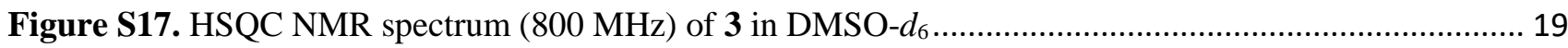

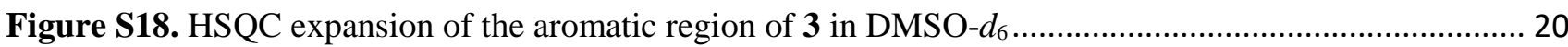

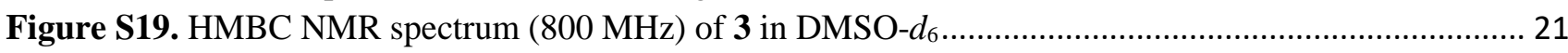

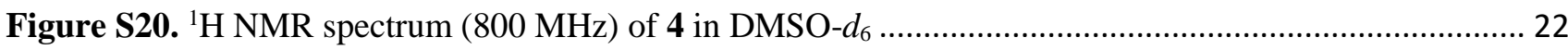

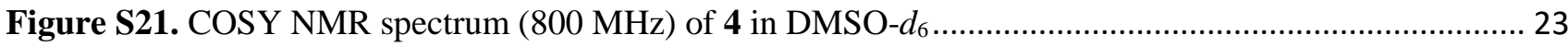

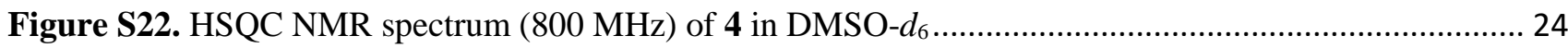

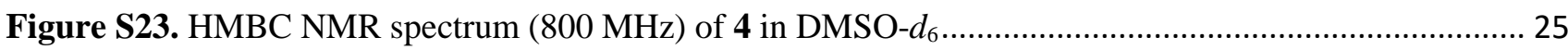

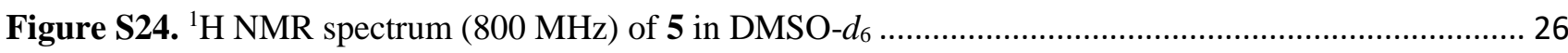

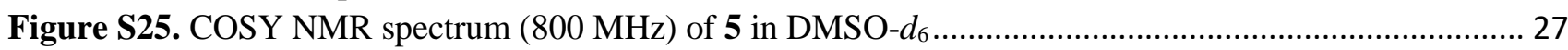

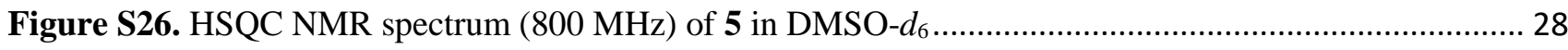

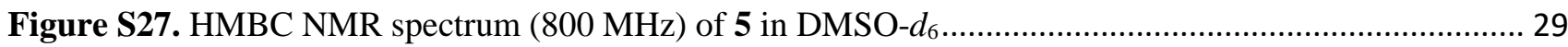

Figure S28. UV absorption spectrum of 3 (from HPLC separation) in $\mathrm{H}_{2} \mathrm{O} / \mathrm{MeOH}(0.1 \%$ TFA) .................. 30

Figure S29. UV absorption spectrum of 4 (from HPLC separation) in $\mathrm{H}_{2} \mathrm{O} / \mathrm{MeOH}(0.1 \%$ TFA) .................. 31

Figure S30. UV absorption spectrum of 5 (from HPLC separation) in $\mathrm{H}_{2} \mathrm{O} / \mathrm{MeOH}(0.1 \%$ TFA) .................. 32 


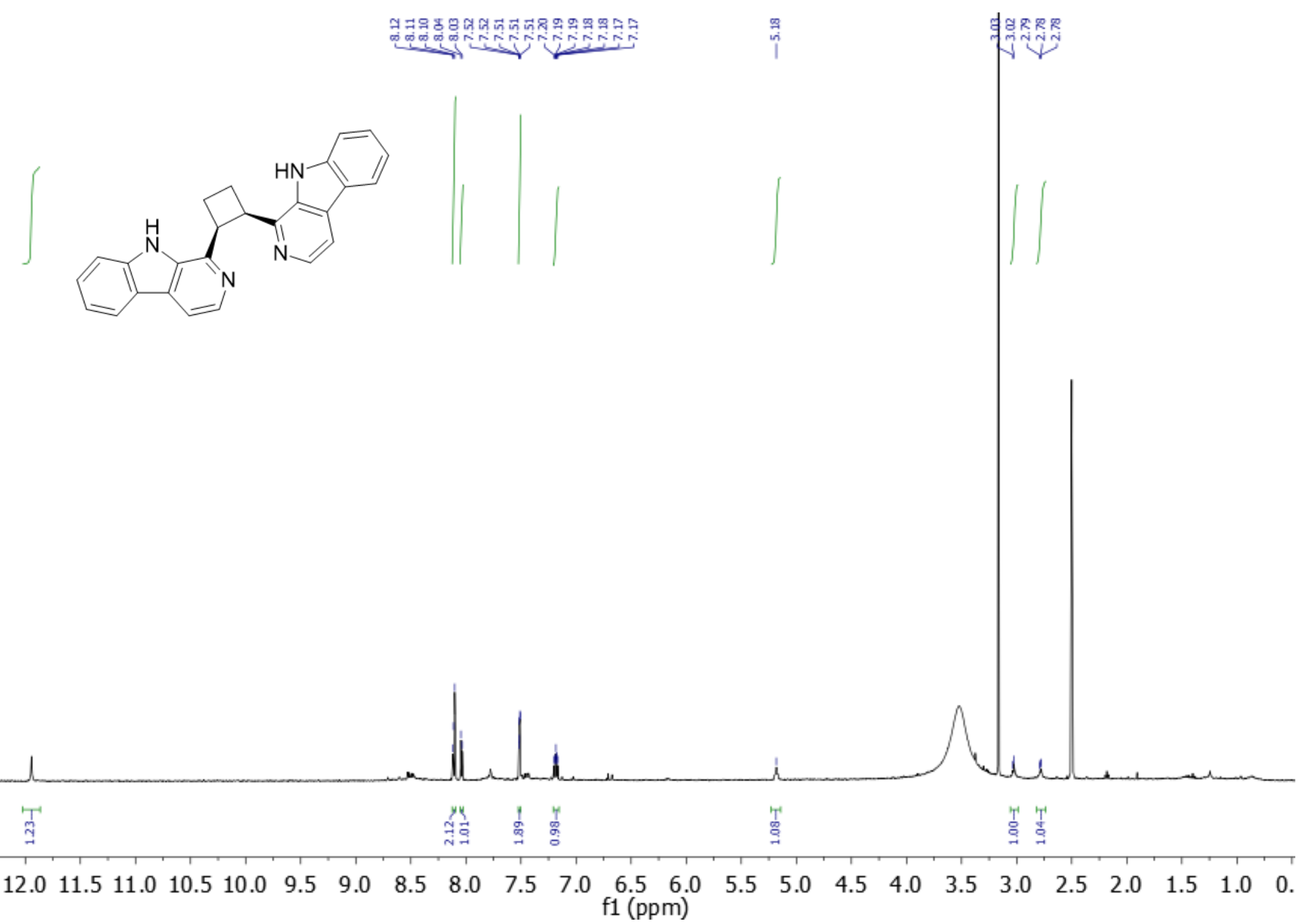

Figure S1. ${ }^{1} \mathrm{H}$ NMR spectrum (800 MHz) of $\mathbf{1}$ in DMSO- $d_{6}$ 


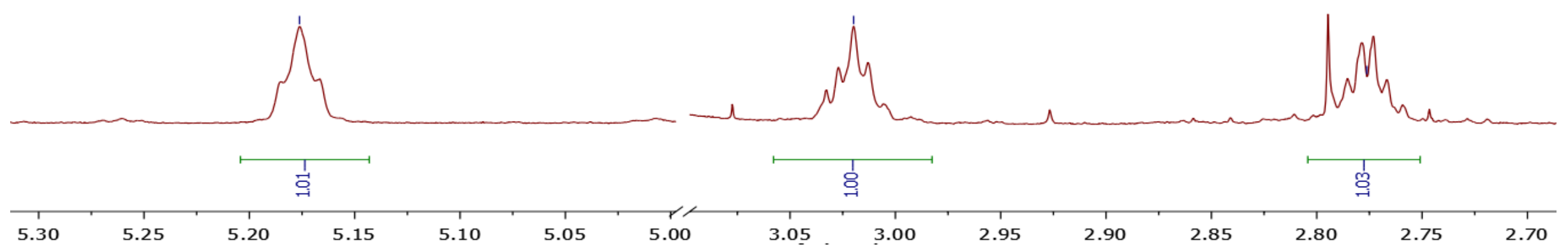

Figure S2. ${ }^{1} \mathrm{H}$ NMR expansion of the cyclobutyl protons of $\mathbf{1}$ (cut out region from 3.10 to $5.00 \mathrm{ppm}$ ) 


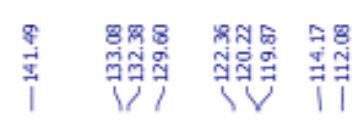

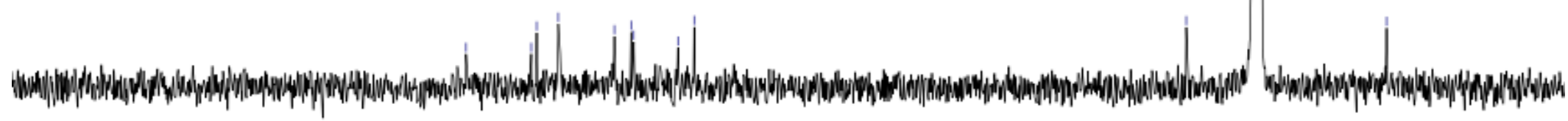

$\begin{array}{lllllllllllllllllllll}0 & 190 & 180 & 170 & 160 & 150 & 140 & 130 & 120 & 110 \underset{\mathrm{f1}(\mathrm{ppm})}{100} & 90 & 80 & 70 & 60 & 50 & 40 & 30 & 20 & 10 & \mathrm{C}\end{array}$

Figure S3. ${ }^{13} \mathrm{C}$ NMR spectrum (800 MHz) of 1 in DMSO- $d_{6}$ 


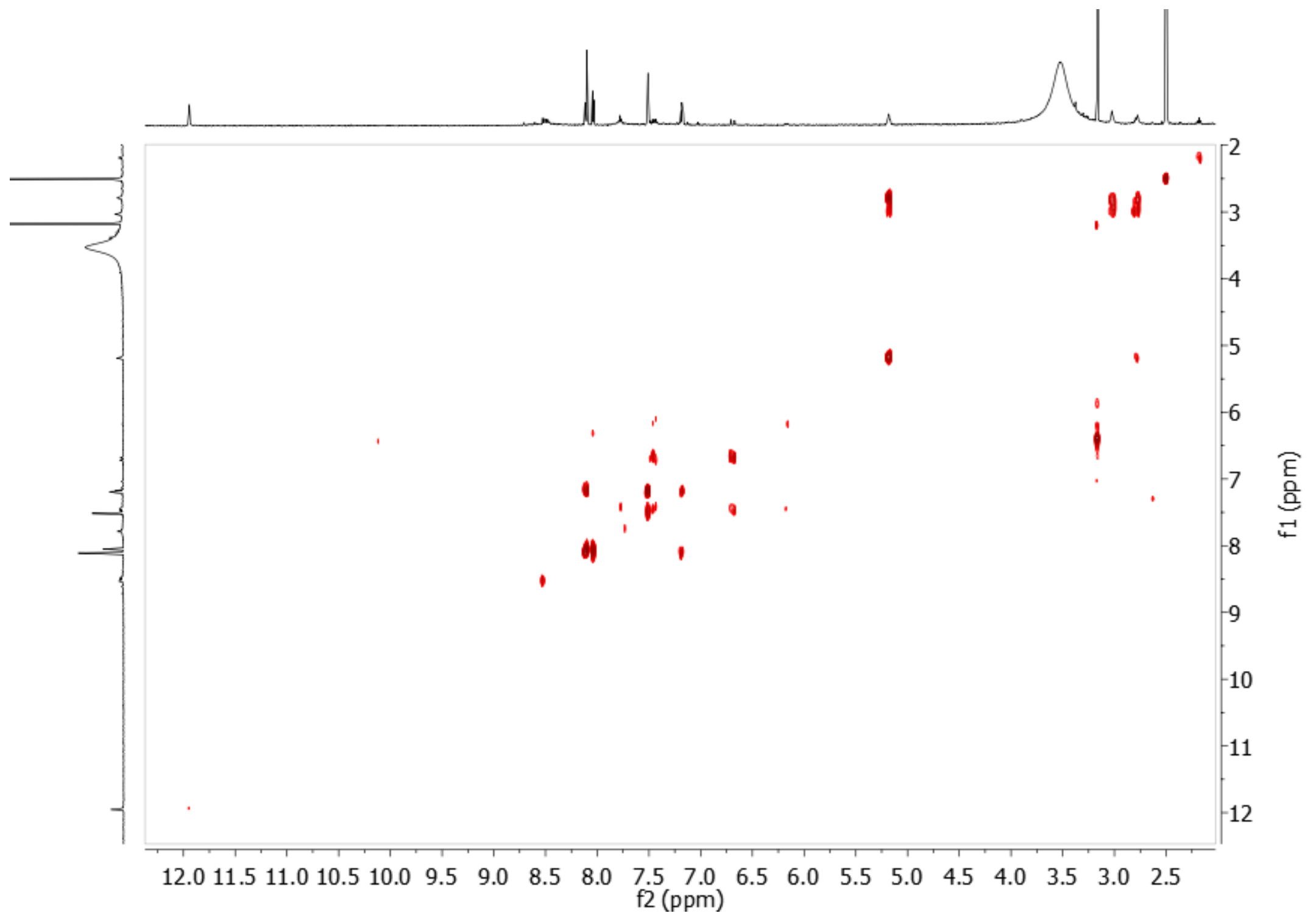

Figure S4. COSY NMR spectrum (800 MHz) of 1 in DMSO- $d_{6}$ 


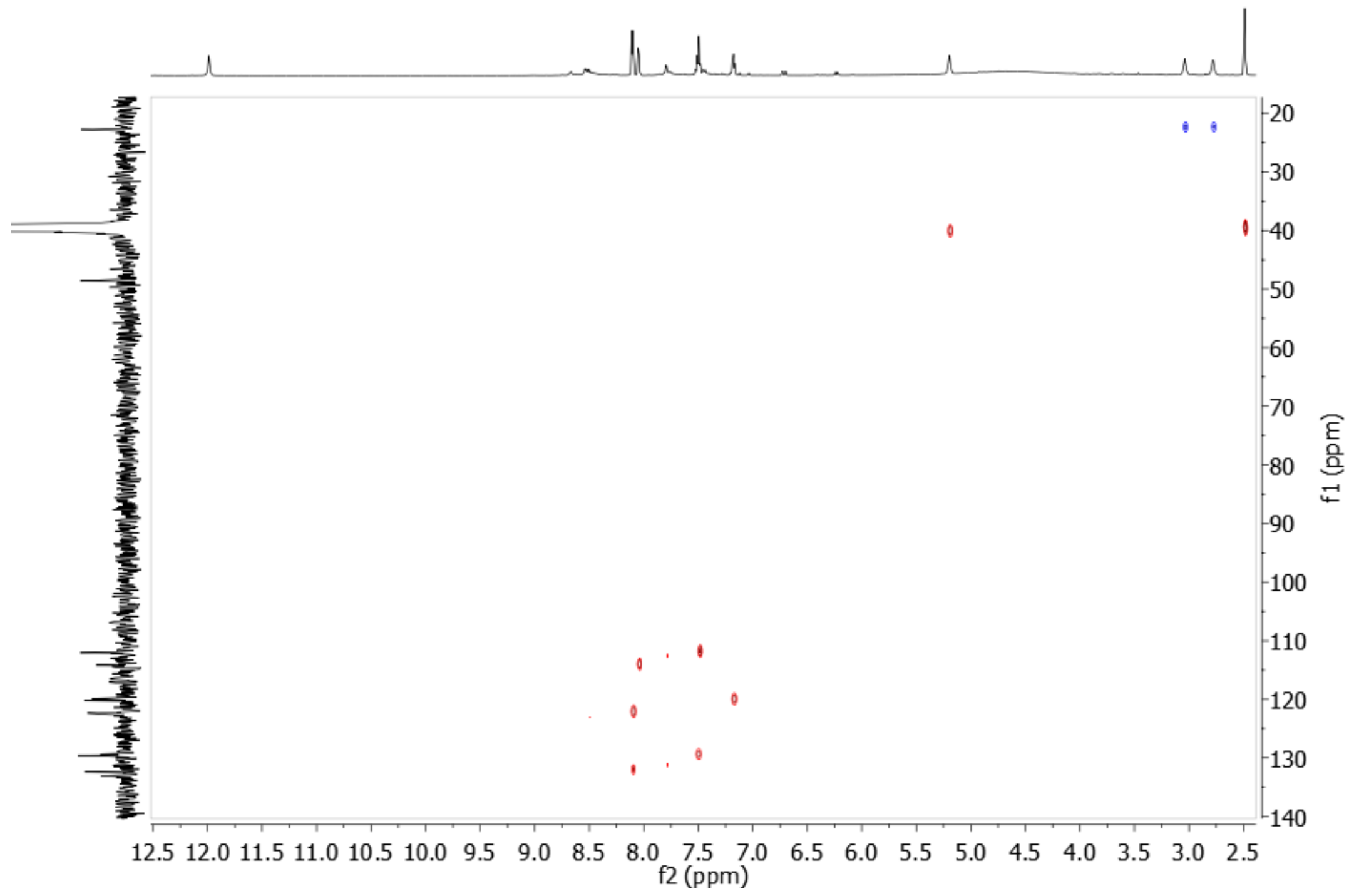

Figure S5. HSQC NMR spectrum (800 MHz) of 1 in DMSO- $d_{6}$ 


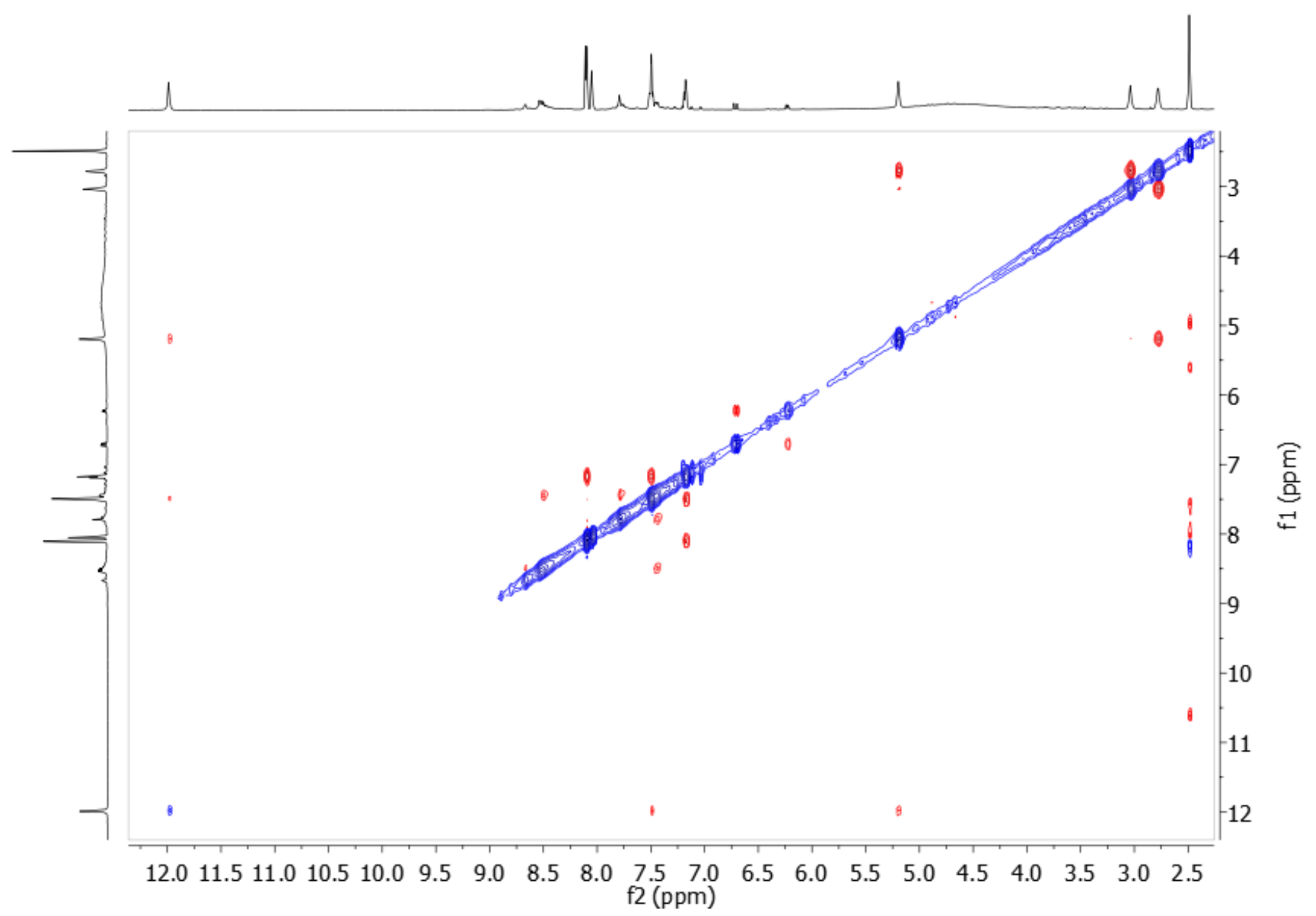

Figure S6. ROESY NMR spectrum (800 MHz) of 1 in DMSO- $d_{6}$ 


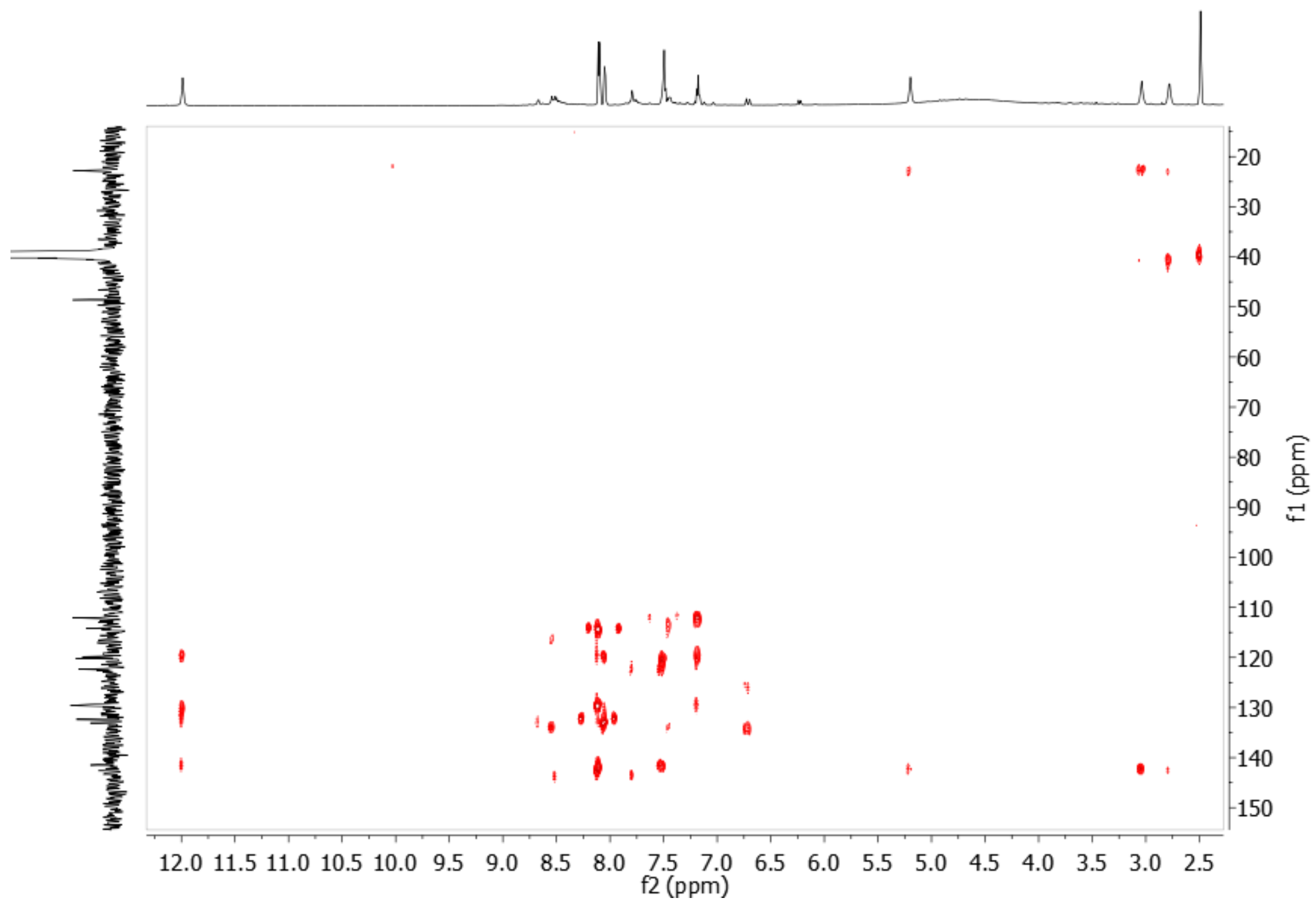

Figure S7. HMBC NMR spectrum (800 MHz) of 1 in DMSO- $d_{6}$ 
$\underset{\substack{N \\ \text { I }}}{1}$

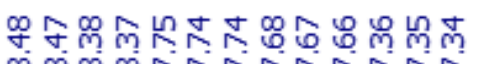

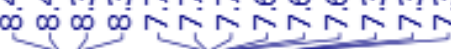

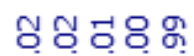

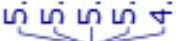

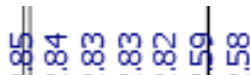

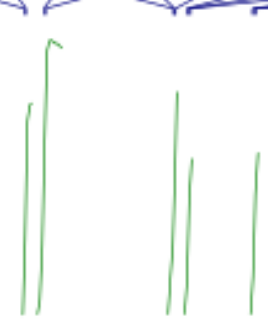

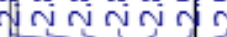
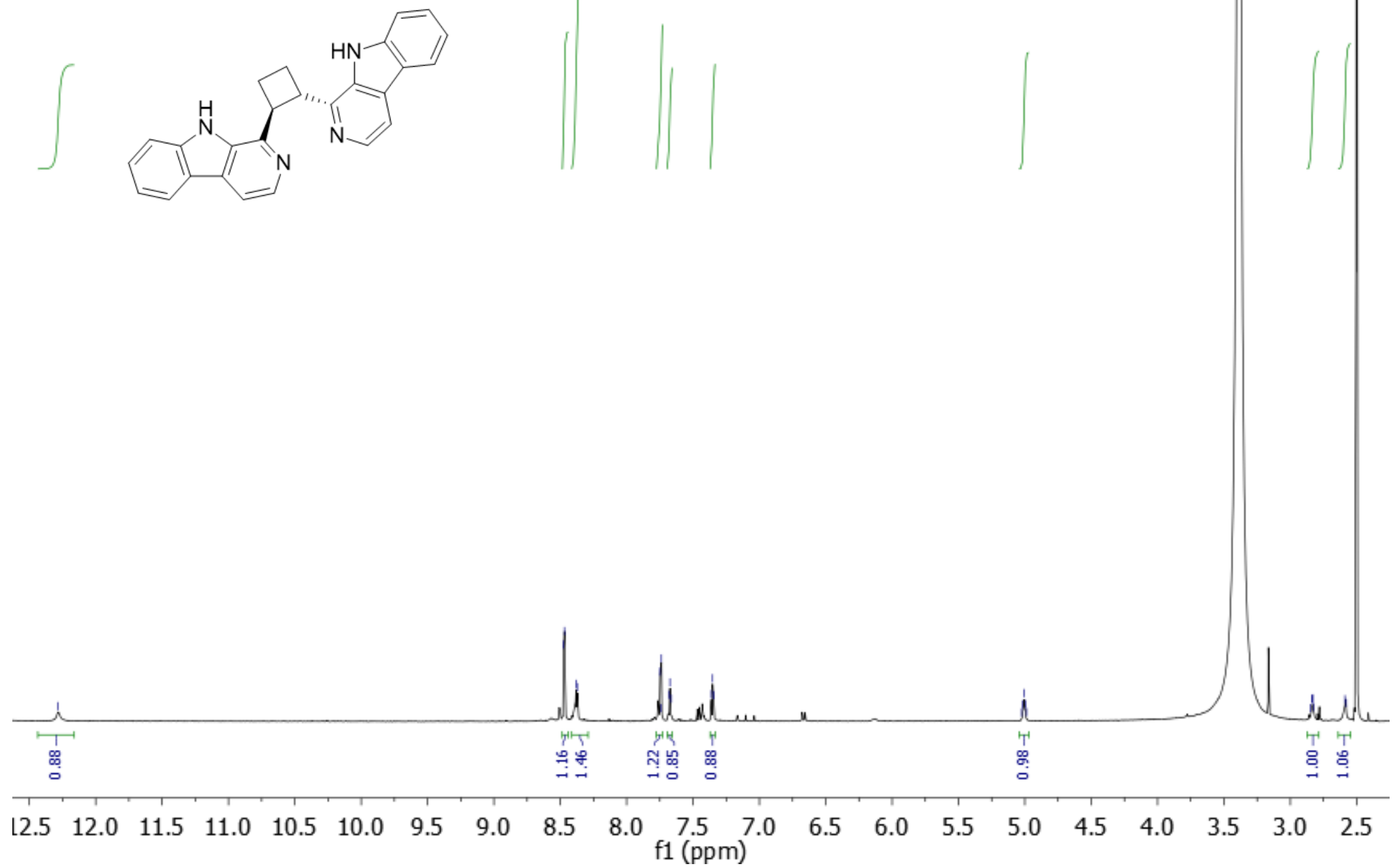

Figure S8. ${ }^{1} \mathrm{H}$ NMR spectrum $(800 \mathrm{MHz})$ of 2 in DMSO- $d_{6}$ 


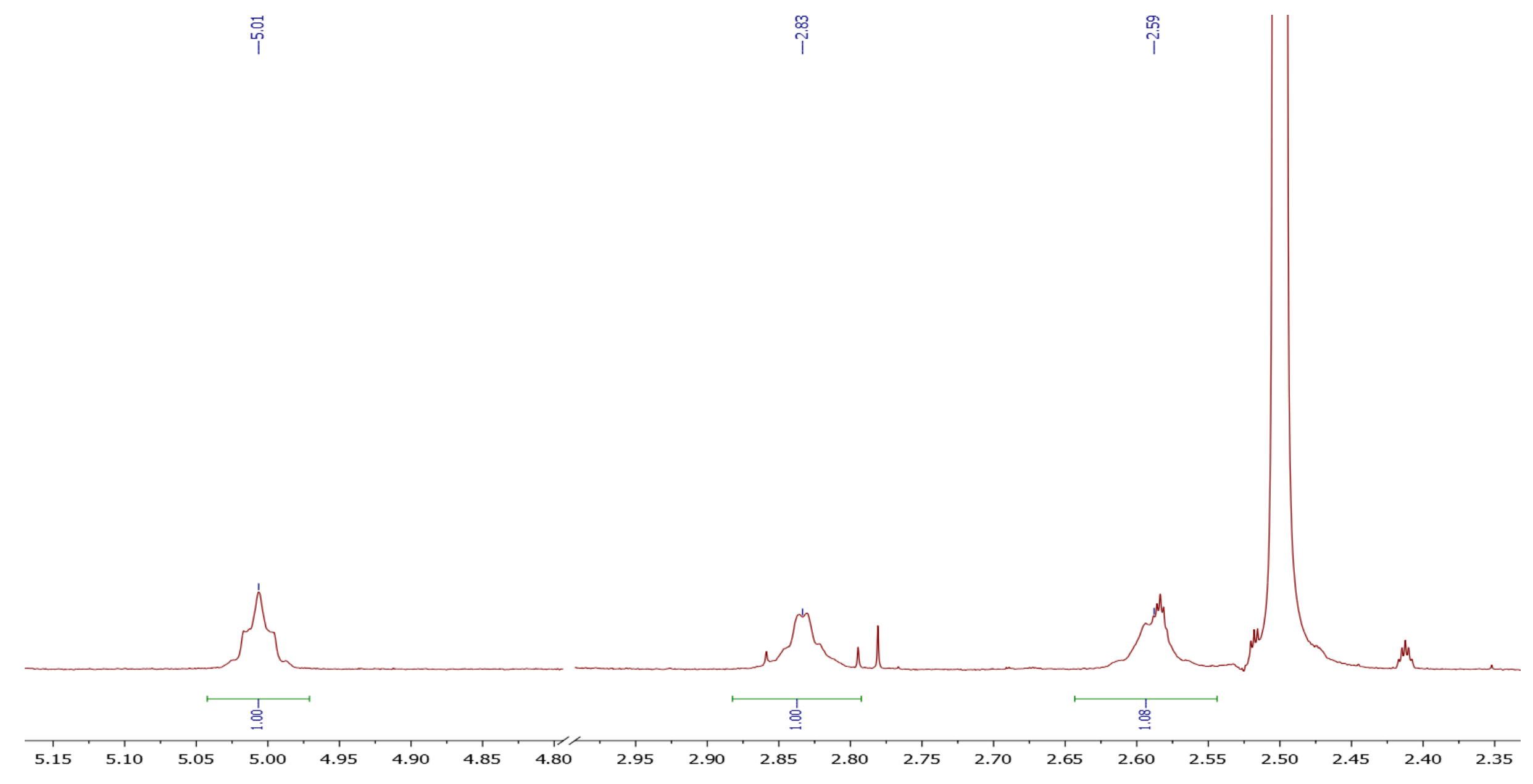

Figure S9. ${ }^{1} \mathrm{H}$ NMR expansion of the cyclobutyl protons of 2 (cut out region from 3.00 to $4.80 \mathrm{ppm}$ ) 


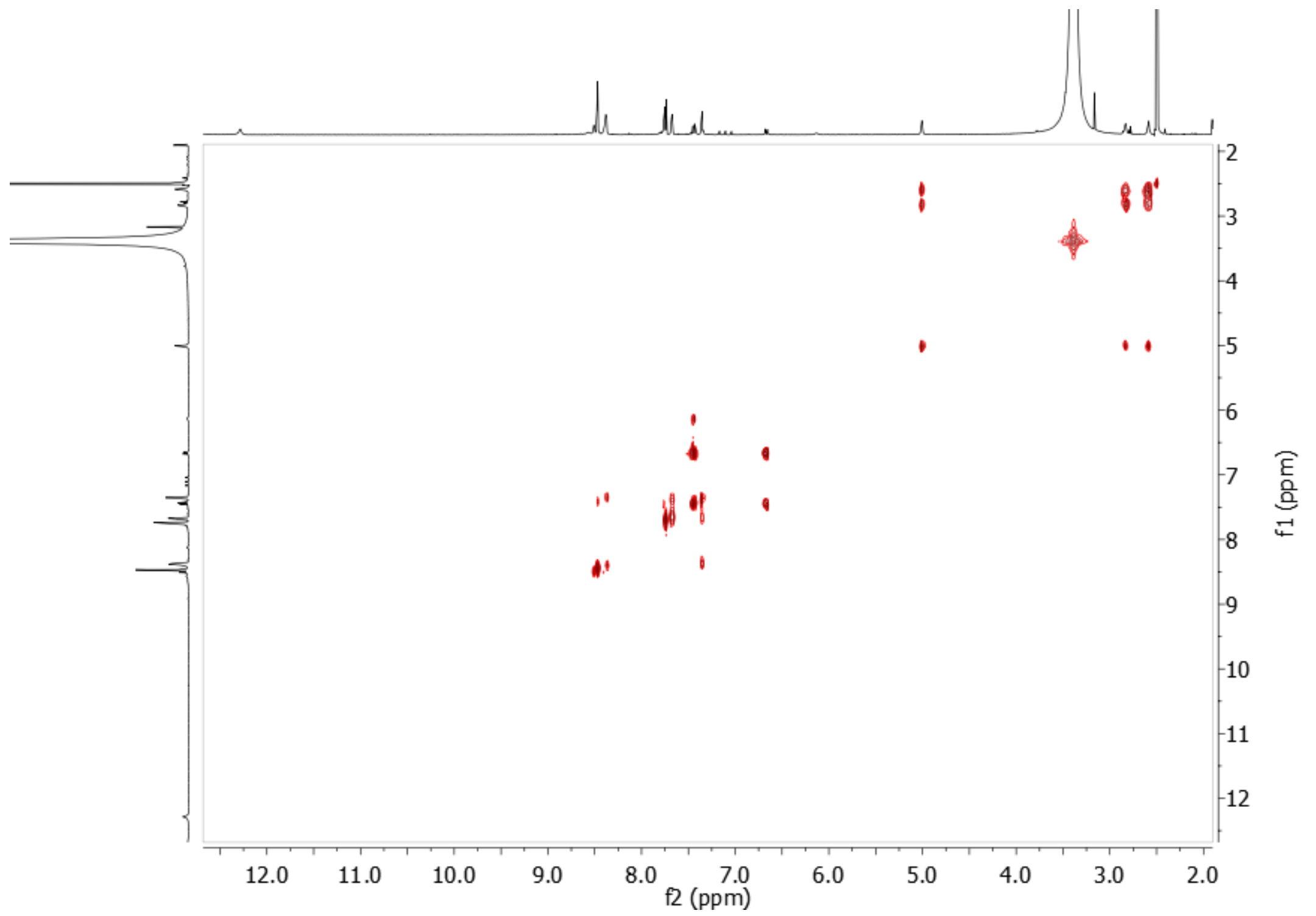

Figure S10. COSY NMR spectrum (800 MHz) of 2 in DMSO- $d_{6}$ 


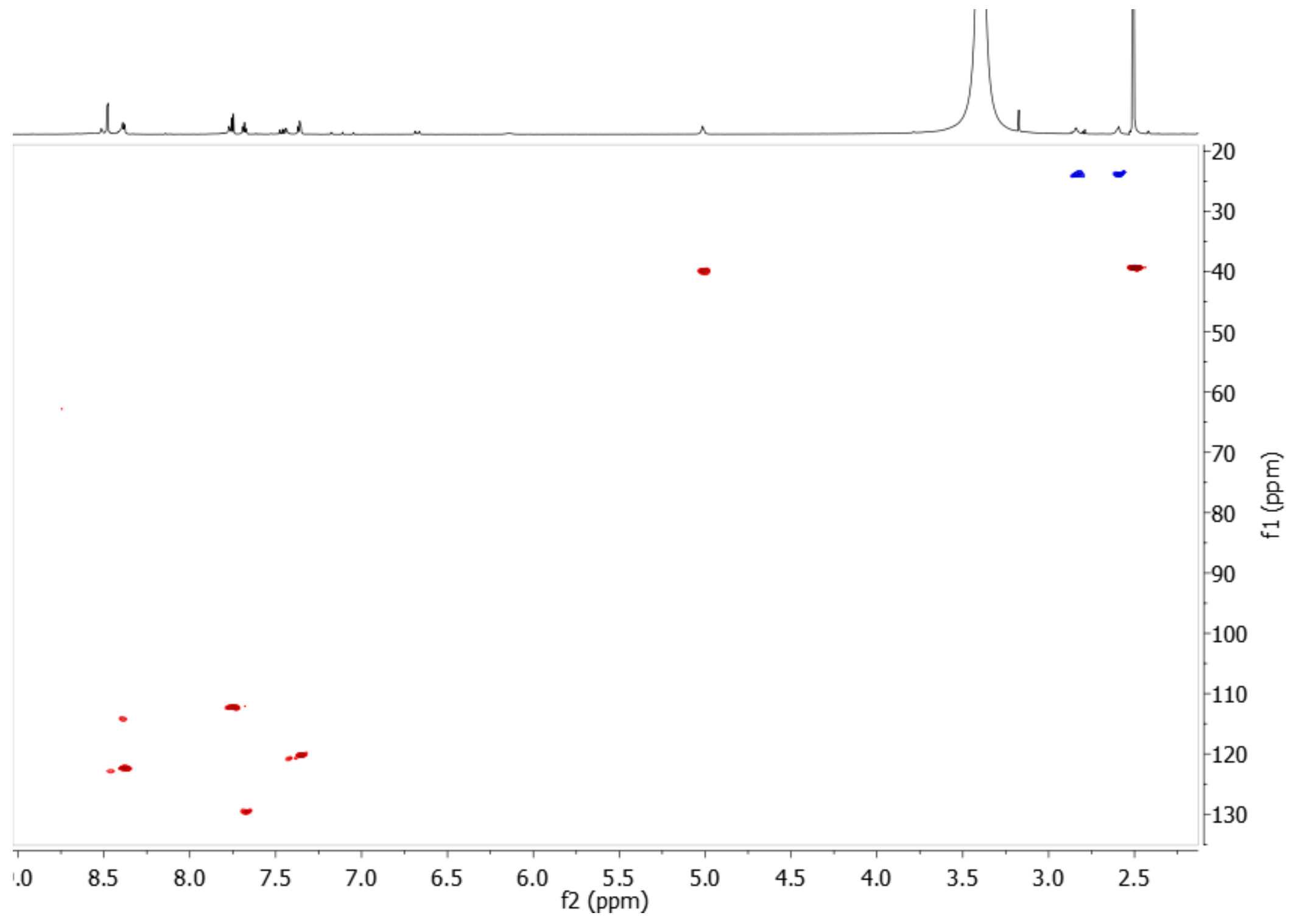

Figure S11. HSQC NMR spectrum (800 MHz) of 2 in DMSO-d 6 


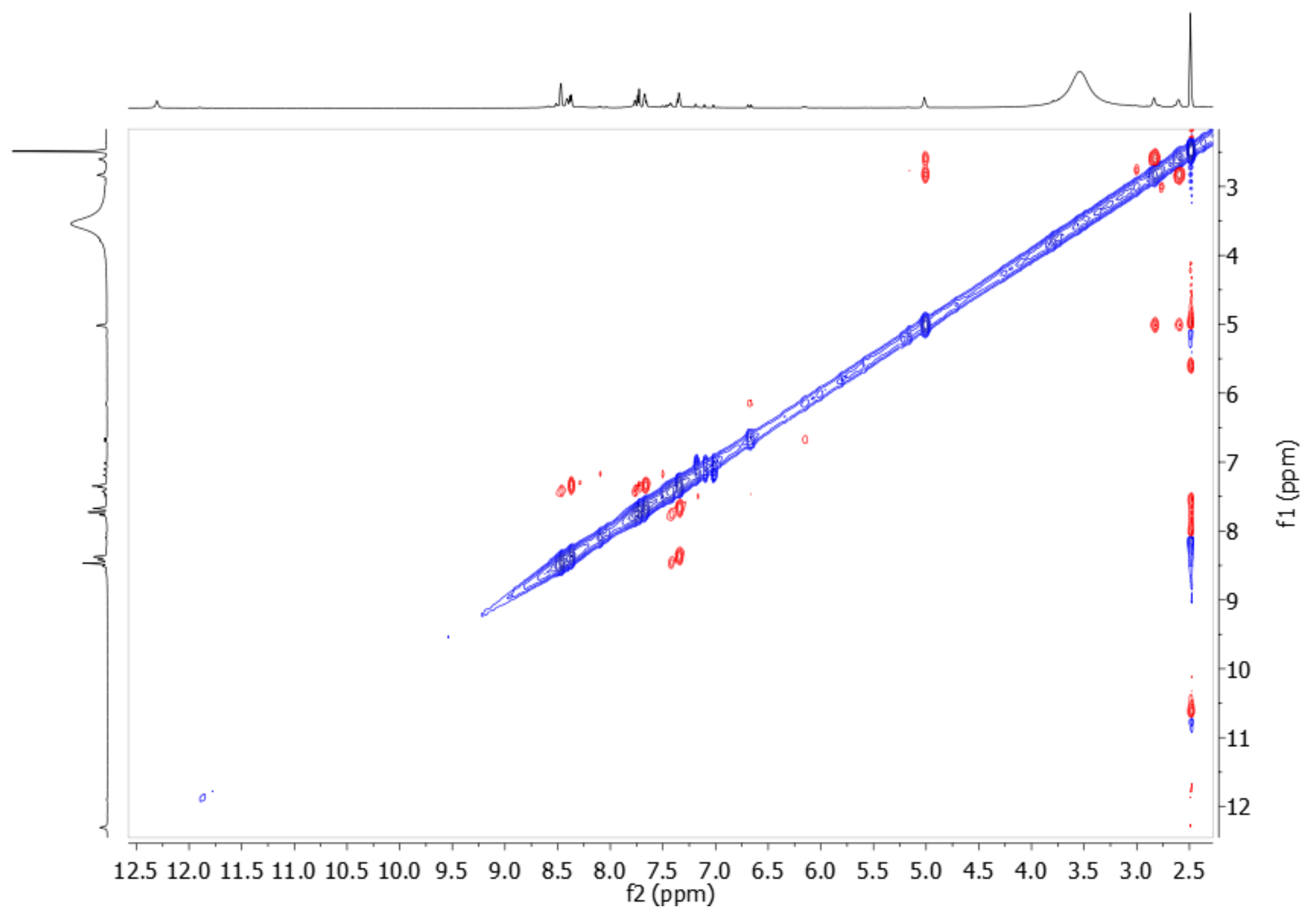

Figure S12. ROESY NMR spectrum (800 MHz) of 2 in DMSO- $d_{6}$ 


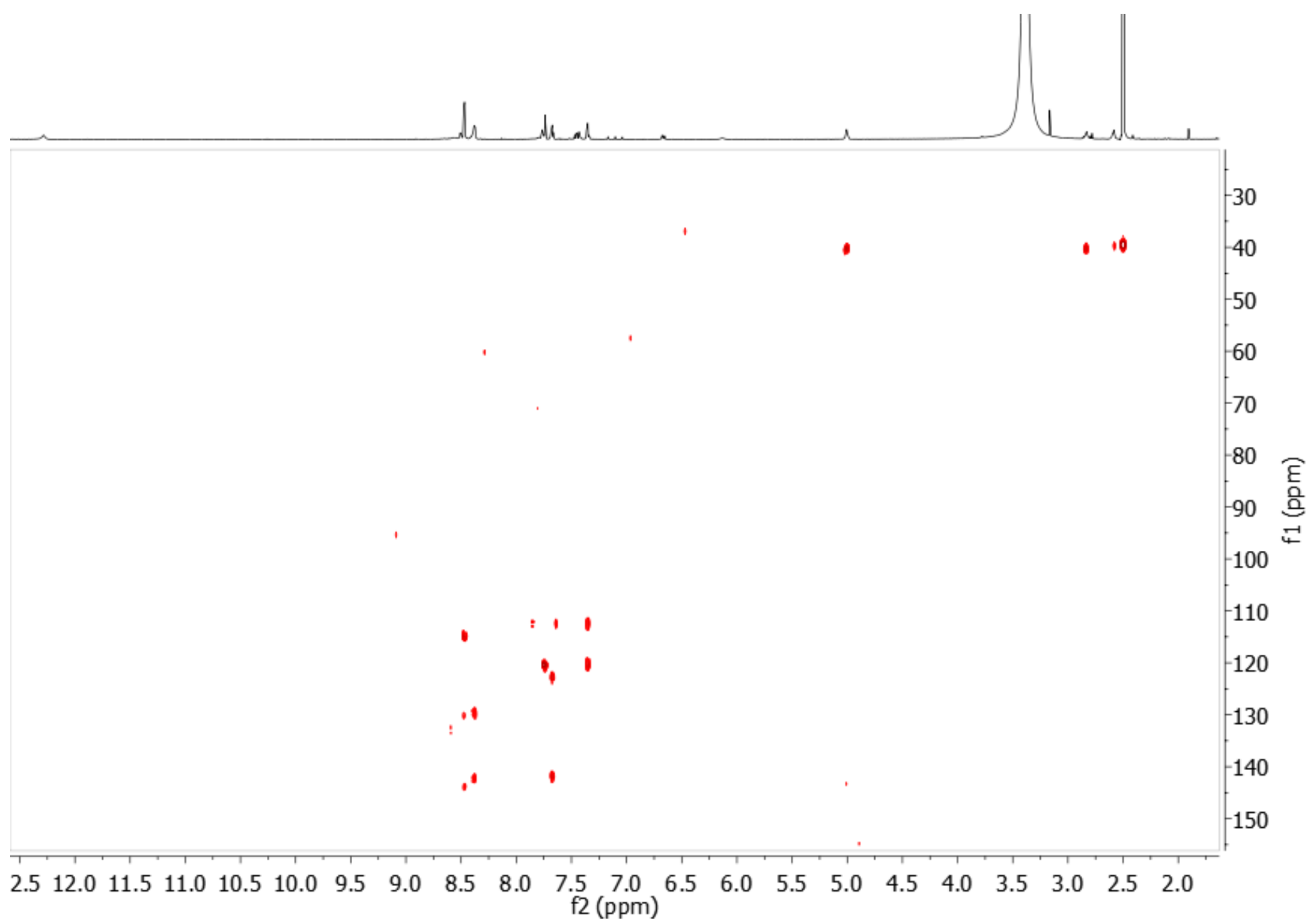

Figure S13. HMBC NMR spectrum (800 MHz) of 2 in DMSO- $d_{6}$ 


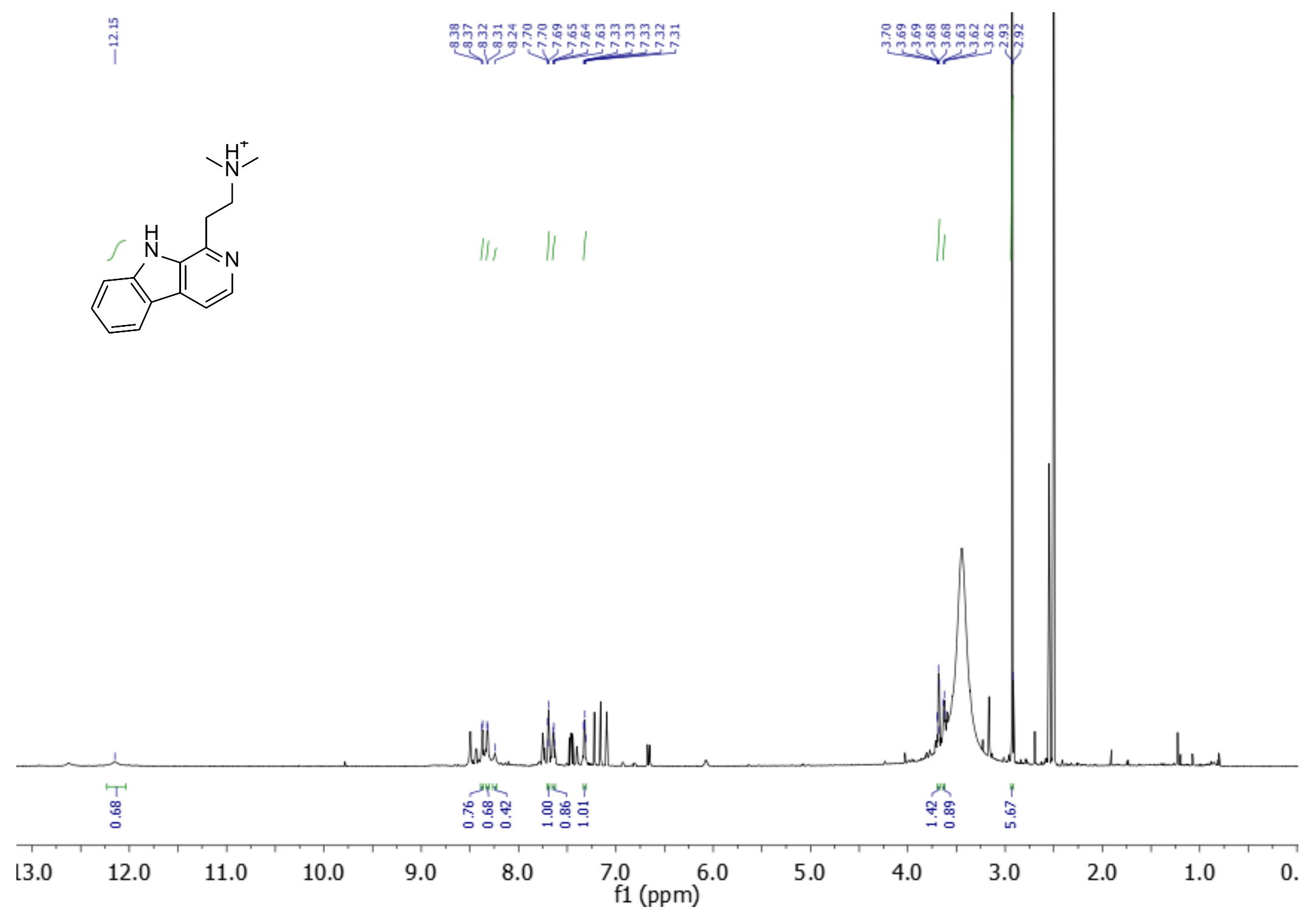

Figure S14. ${ }^{1} \mathrm{H}$ NMR spectrum (800 MHz) of the TFA salt of 3 in DMSO-d $d_{6}$ 


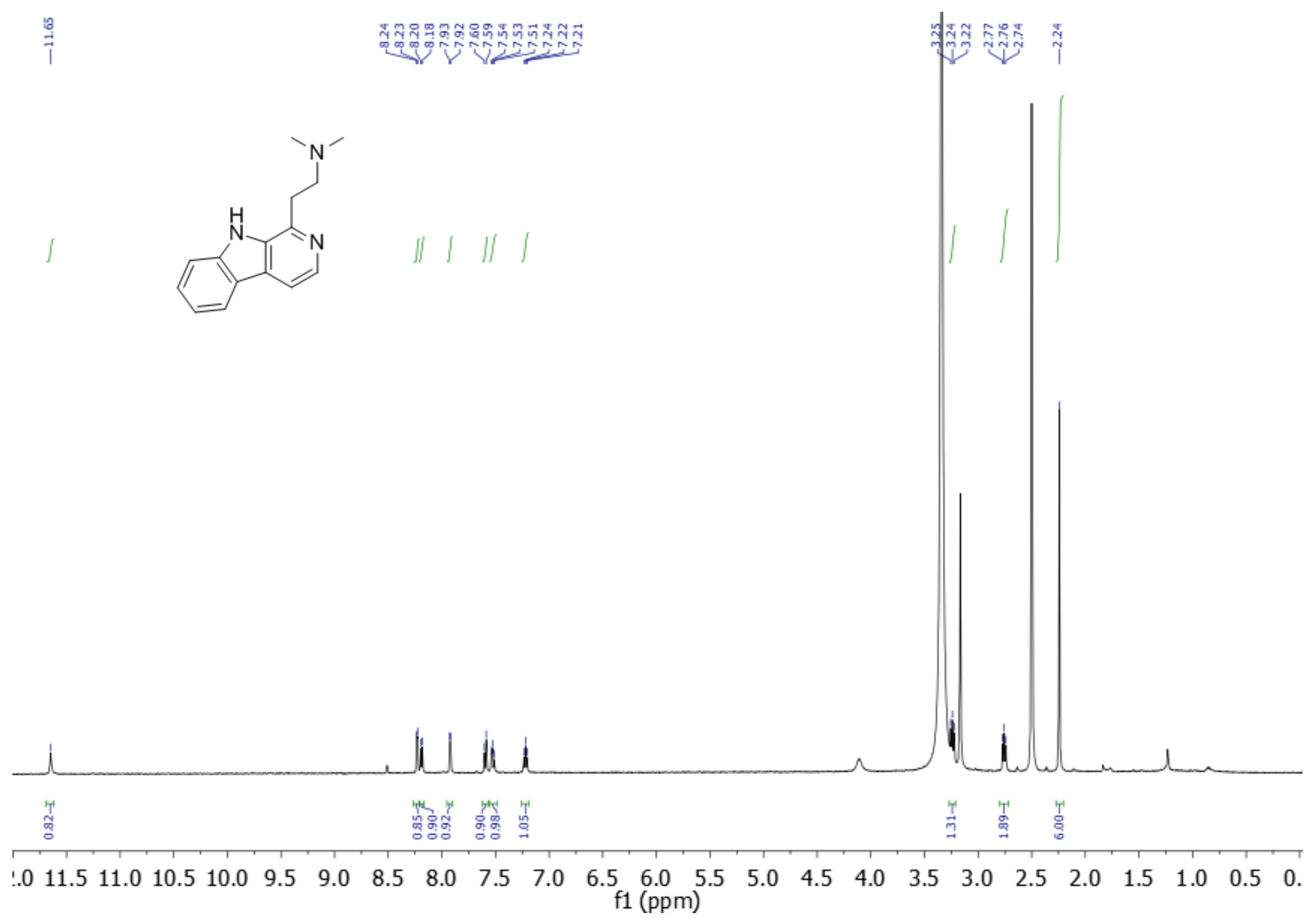

Figure S15. ${ }^{1} \mathrm{H}$ NMR spectrum $(500 \mathrm{MHz})$ of the free-base form of 3 in DMSO- $d_{6}$ 


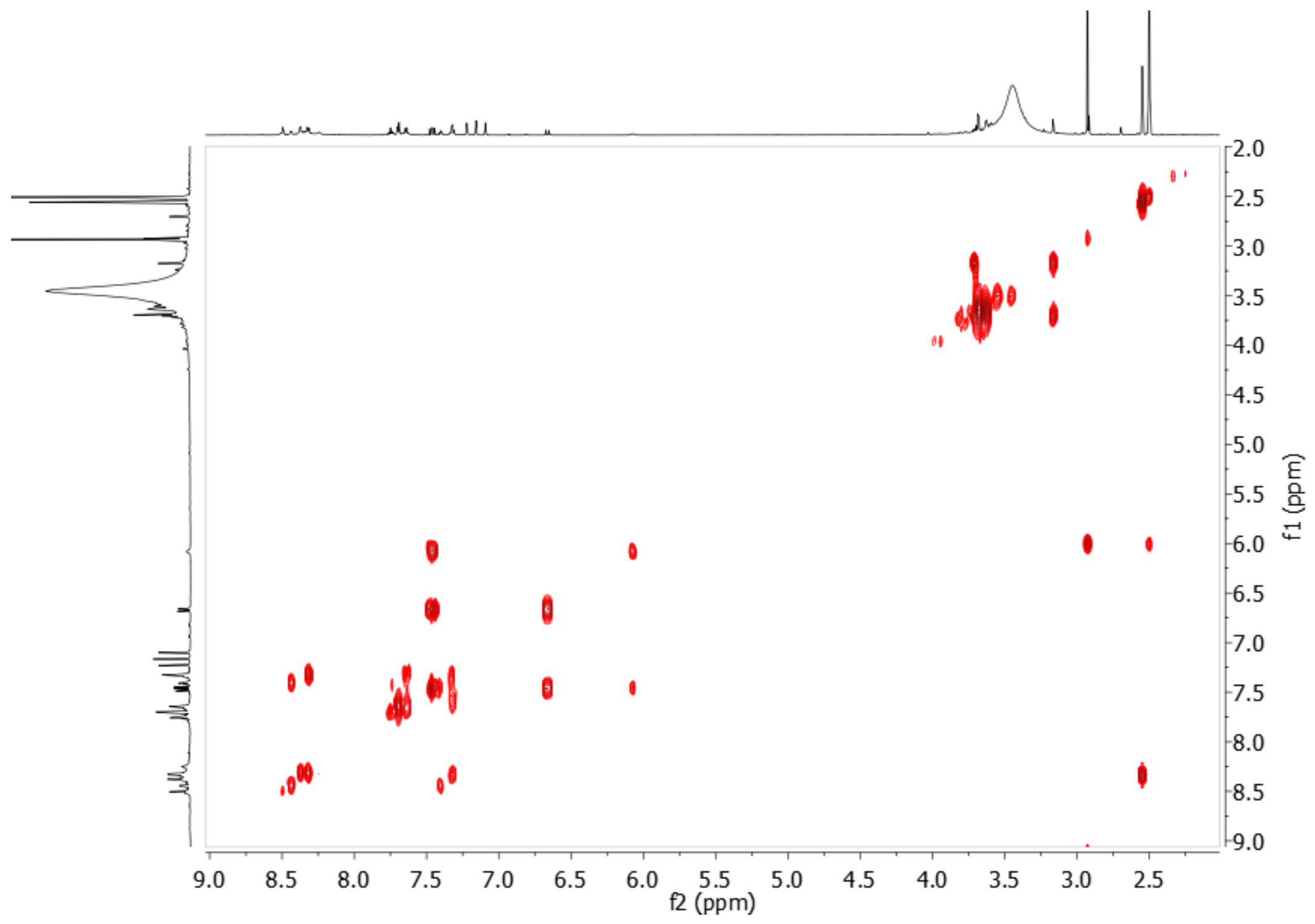

Figure S16. COSY NMR spectrum (800 MHz) of 3 in DMSO- $d_{6}$ 


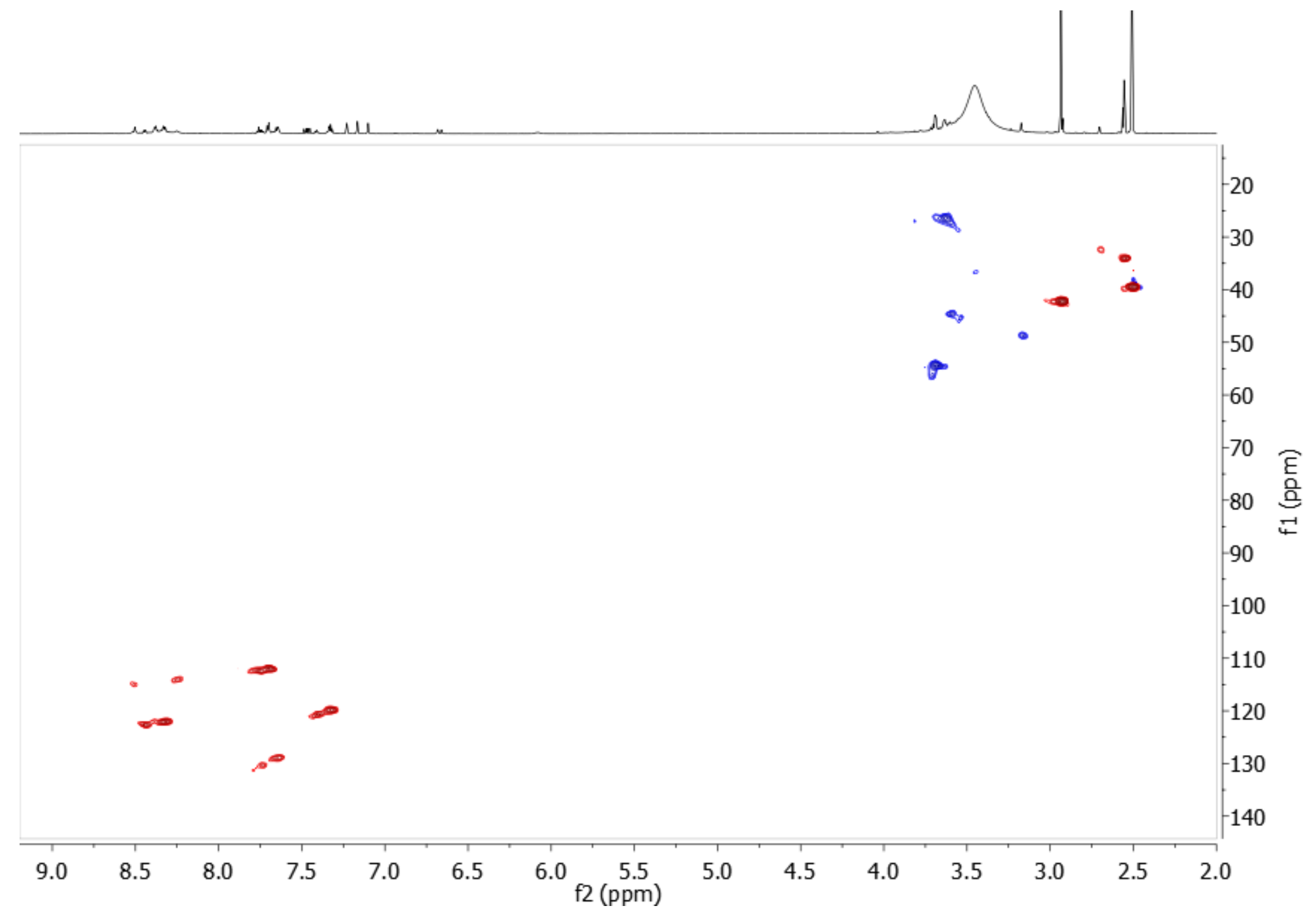

Figure S17. HSQC NMR spectrum (800 MHz) of 3 in DMSO- $d_{6}$ 


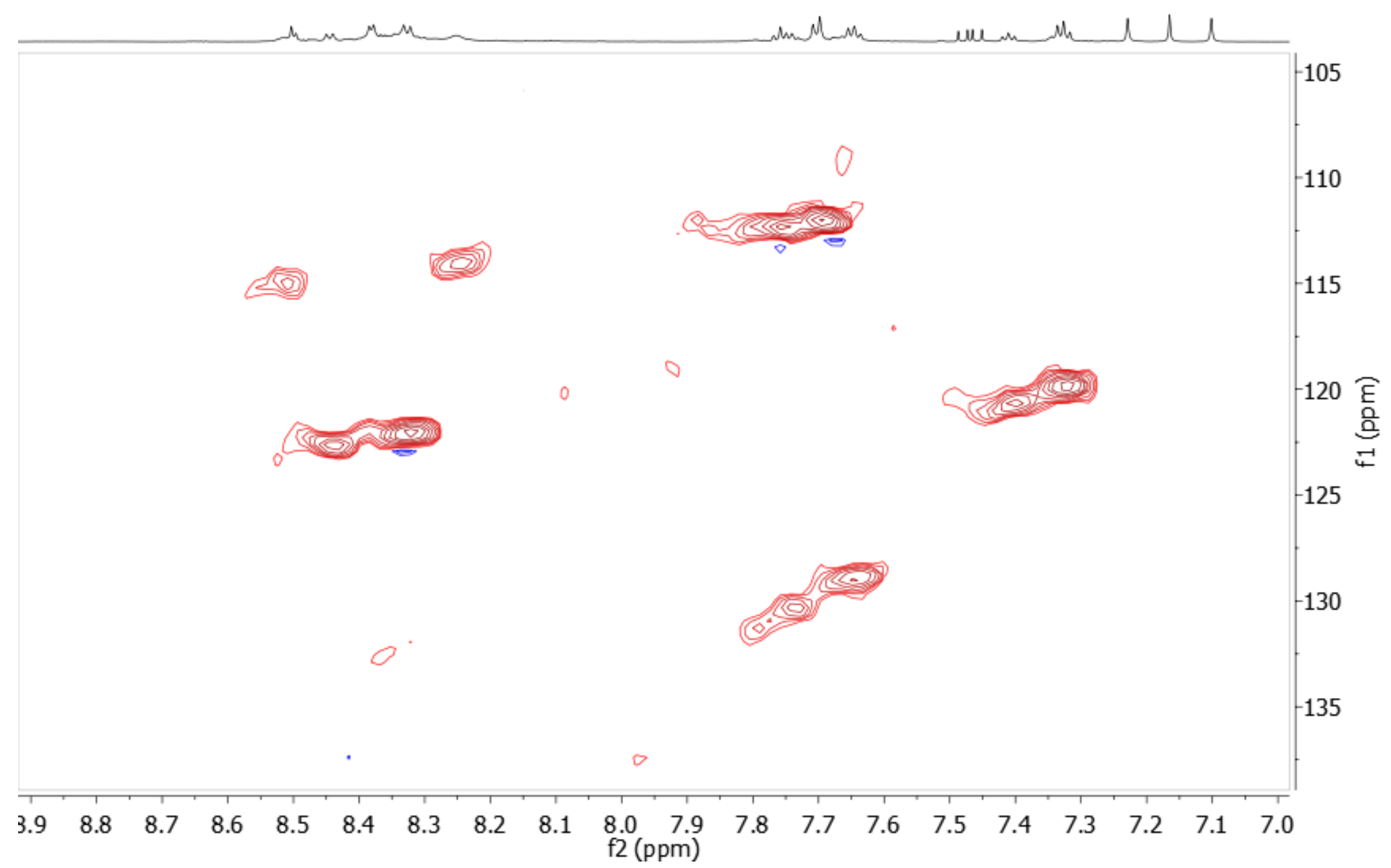

Figure S18. HSQC expansion of the aromatic region of $\mathbf{3}$ in DMSO- $d_{6}$ 


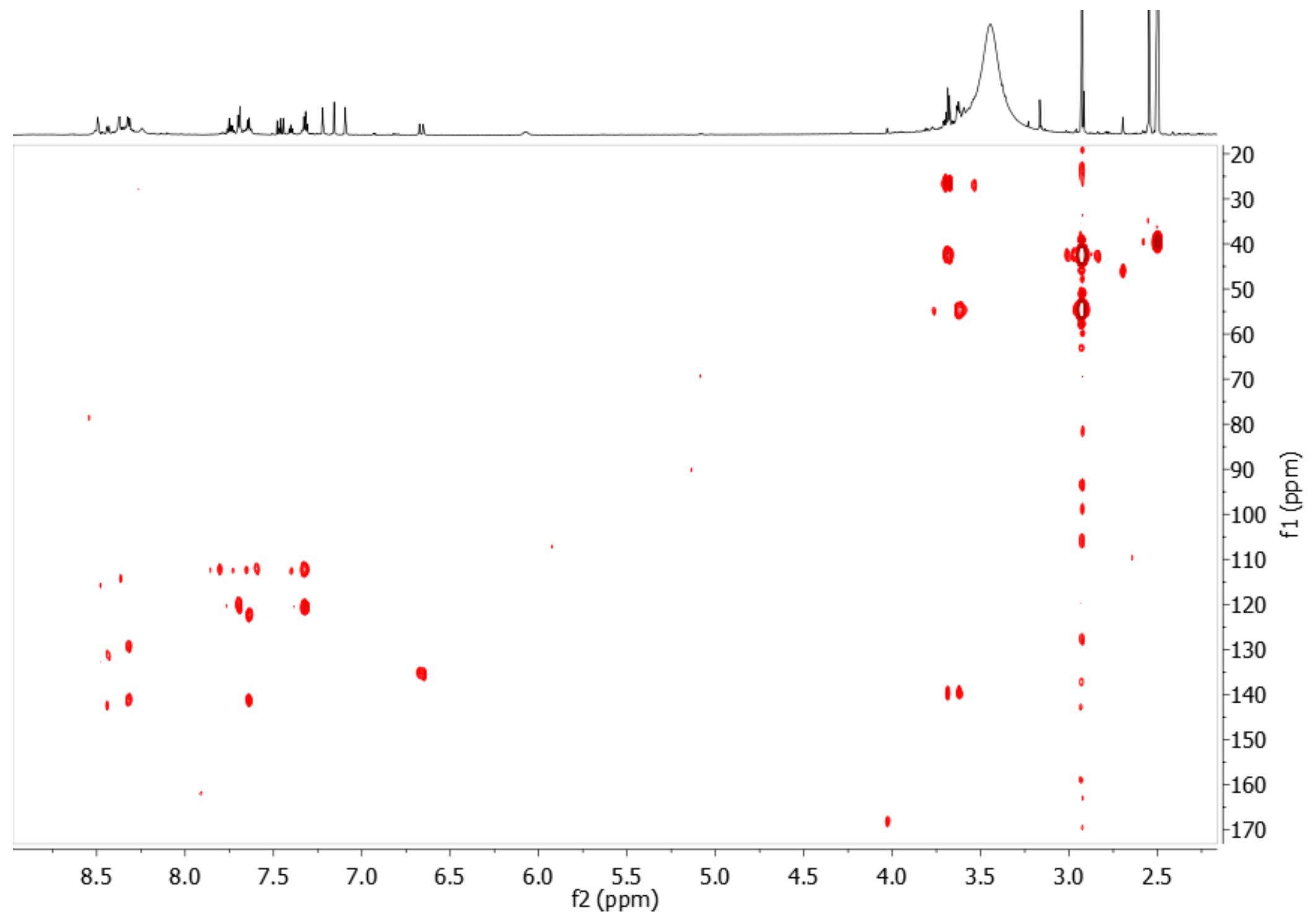

Figure S19. HMBC NMR spectrum (800 MHz) of 3 in DMSO- $d_{6}$ 


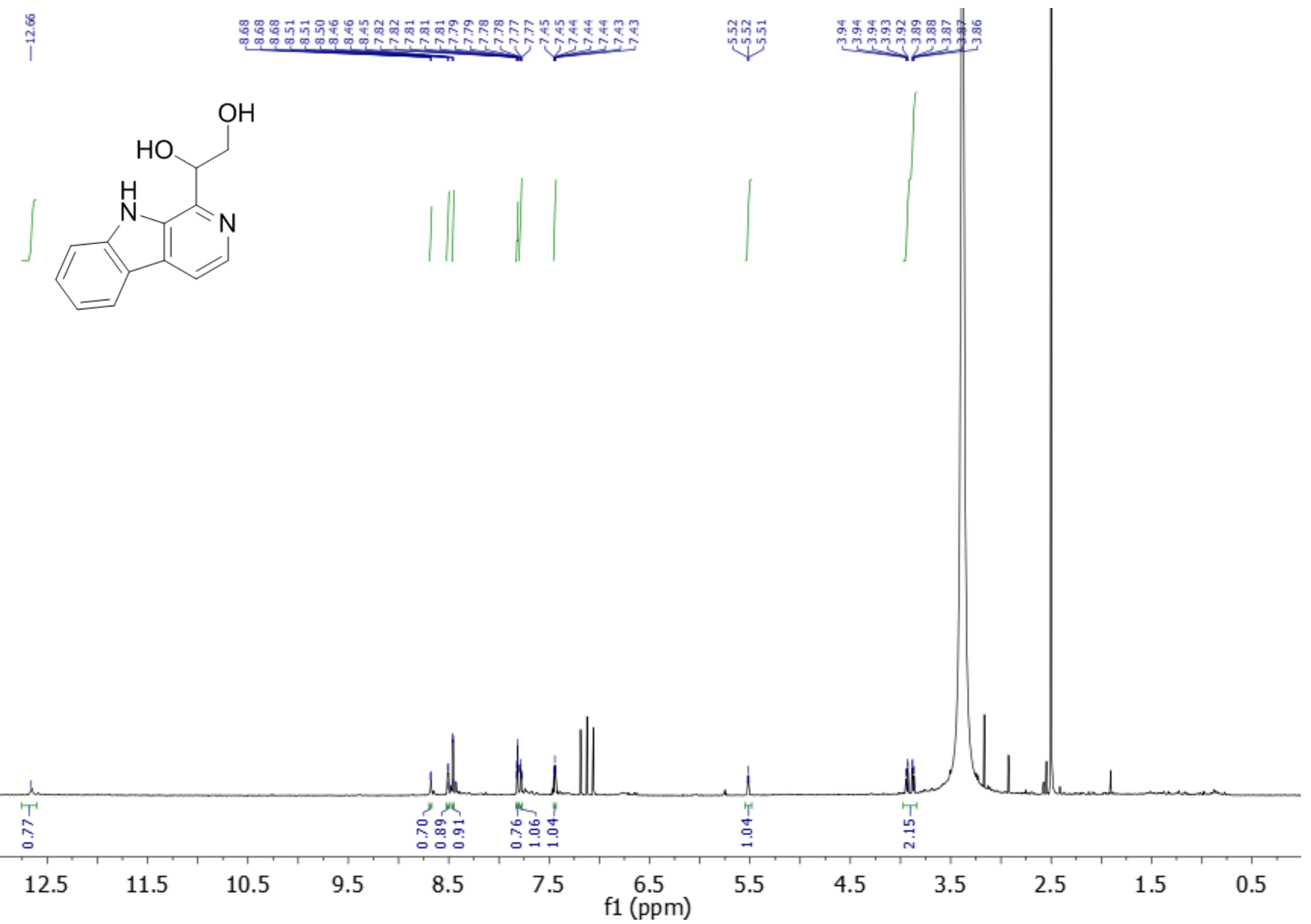

Figure S20. ${ }^{1} \mathrm{H}$ NMR spectrum $(800 \mathrm{MHz})$ of $\mathbf{4}$ in DMSO- $d_{6}$ 


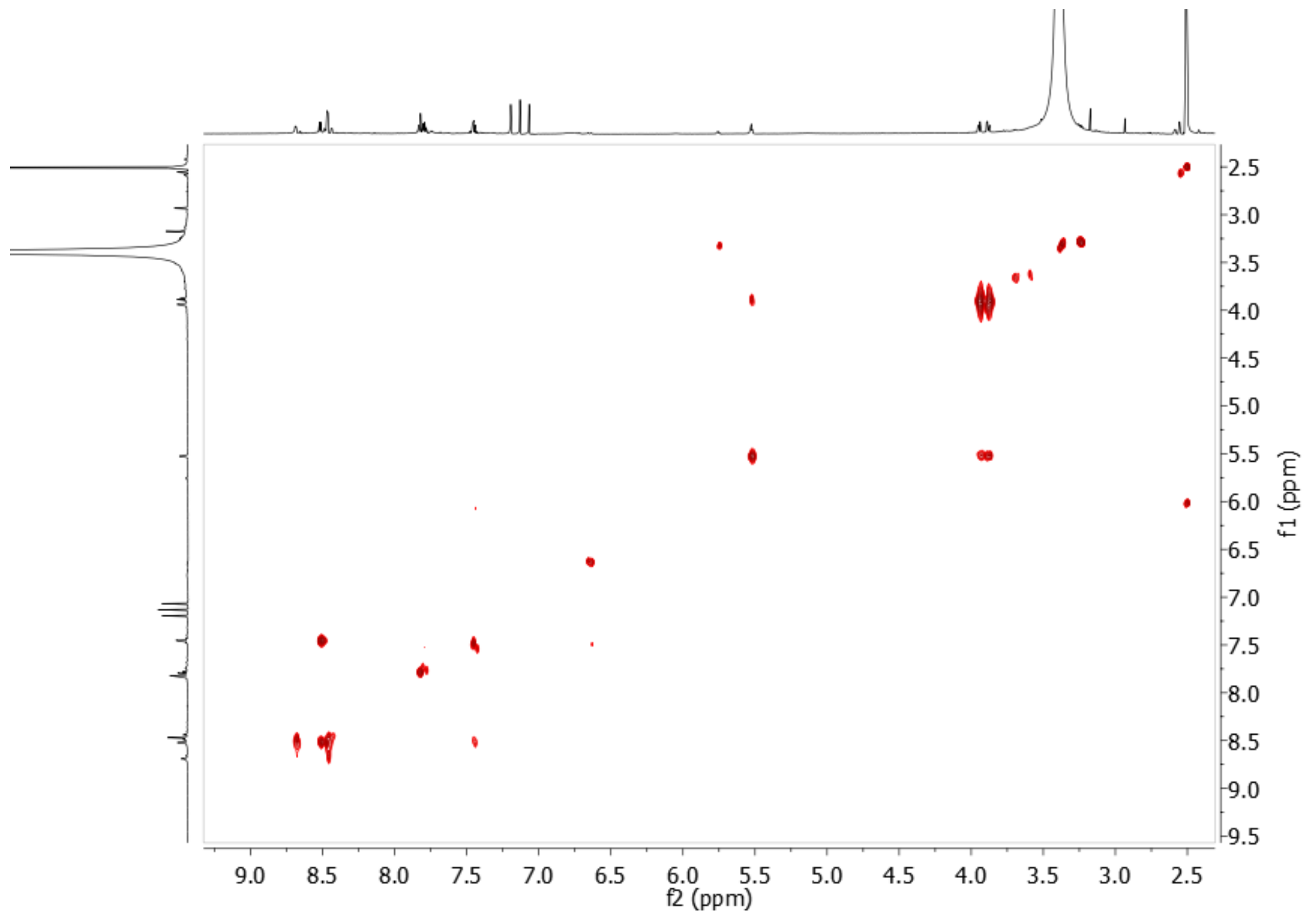

Figure S21. COSY NMR spectrum (800 MHz) of 4 in DMSO-d $d_{6}$ 


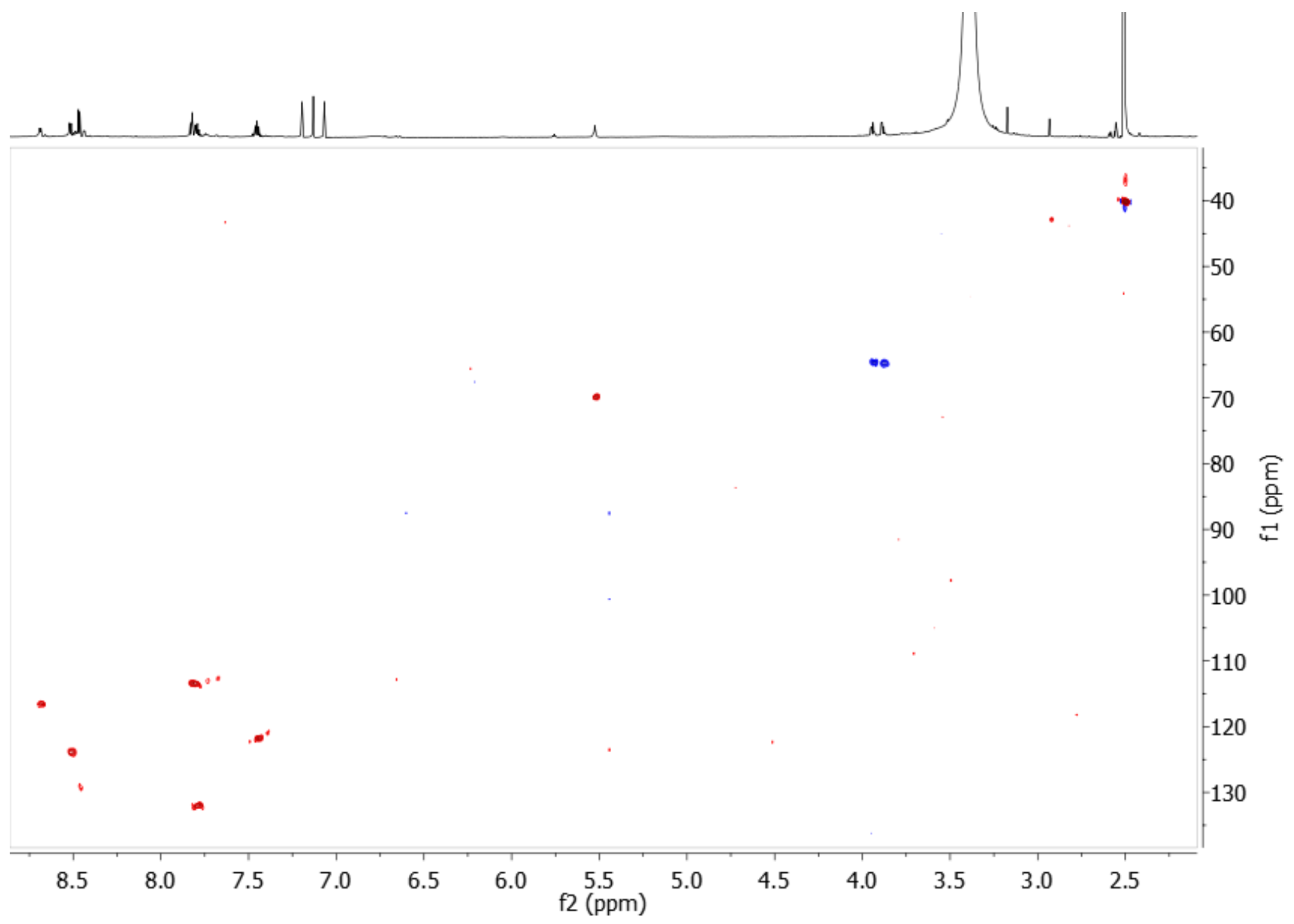

Figure S22. HSQC NMR spectrum (800 MHz) of 4 in DMSO- $d_{6}$ 


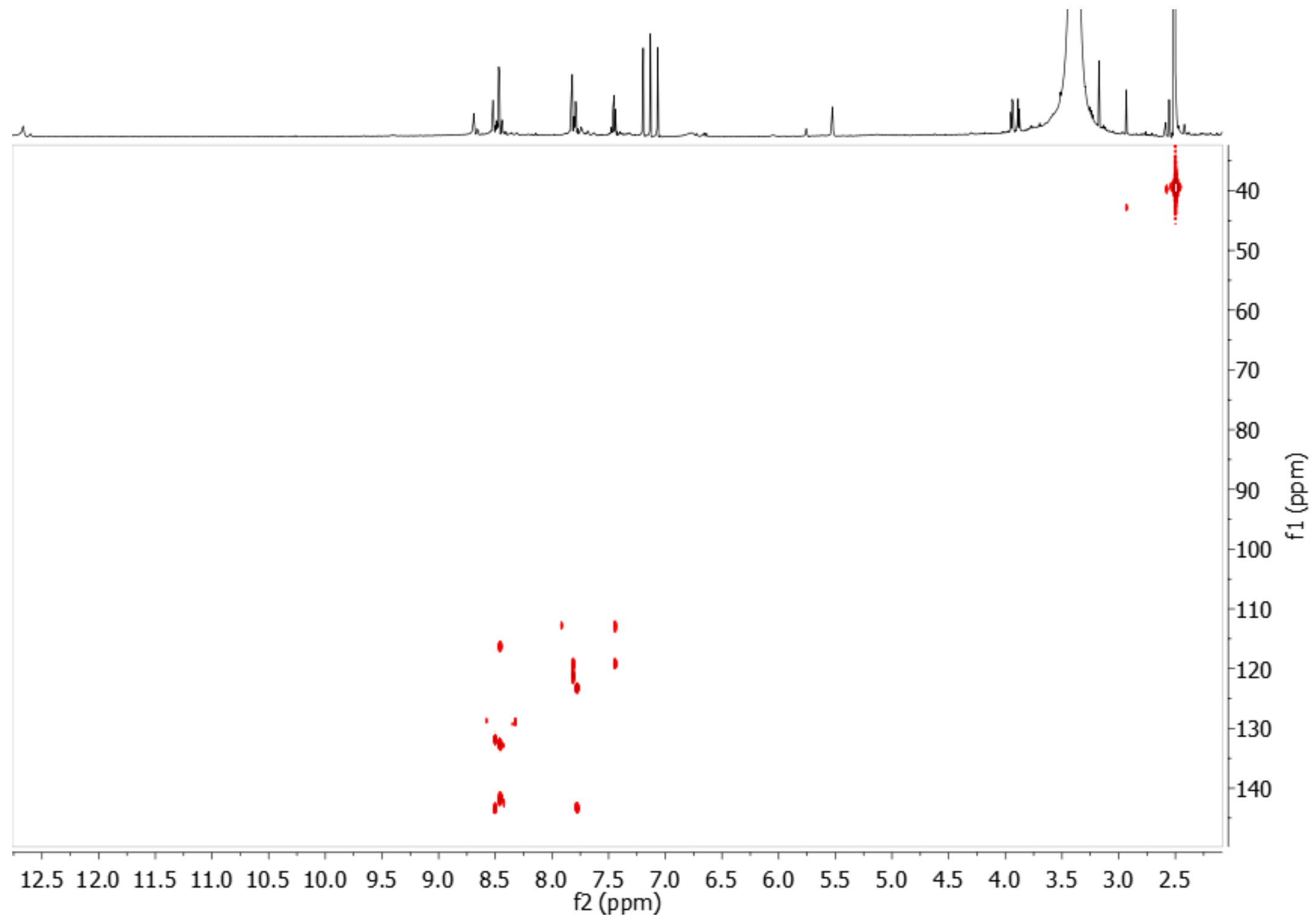

Figure S23. HMBC NMR spectrum (800 MHz) of 4 in DMSO- $d_{6}$ 

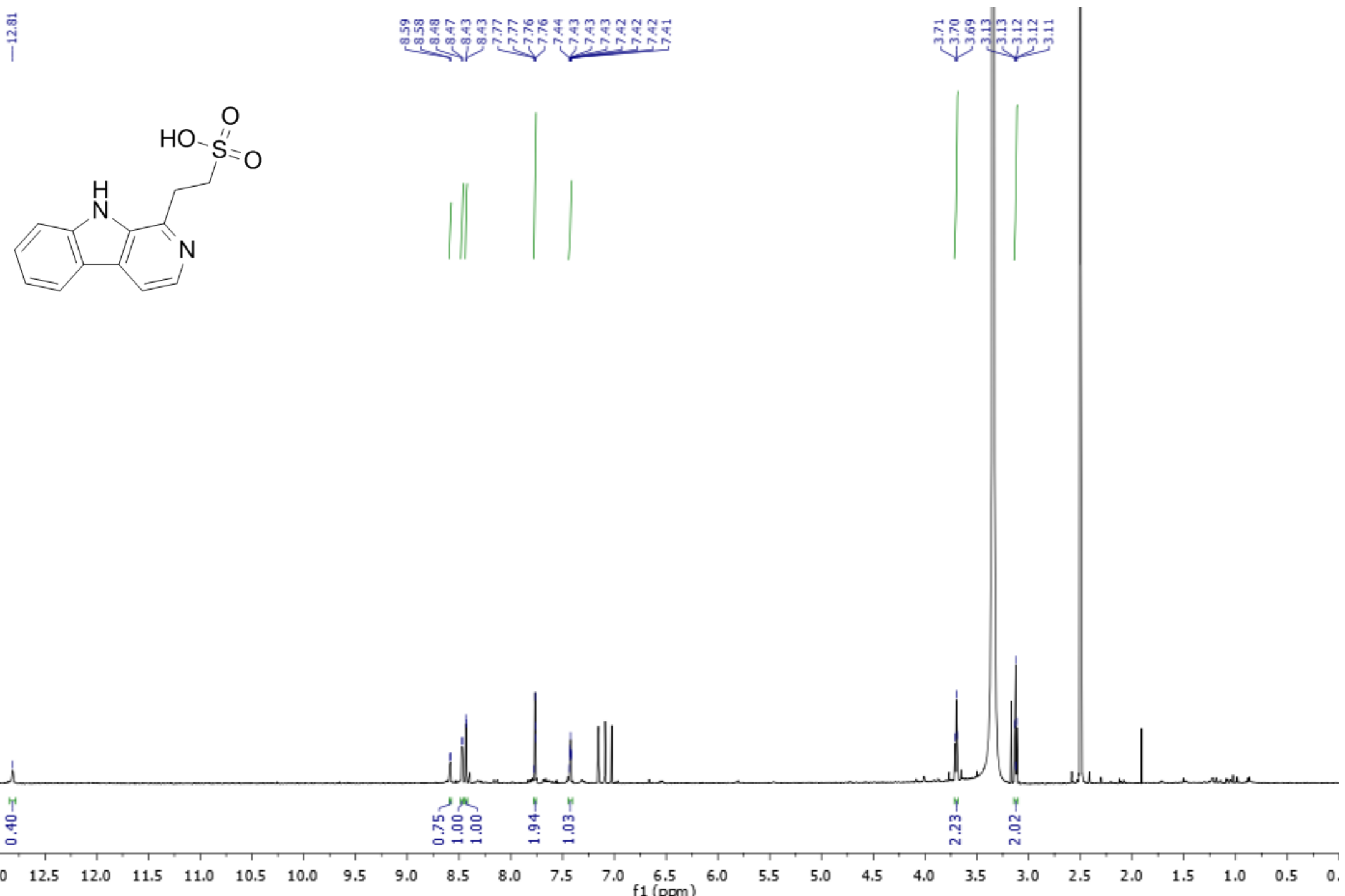

Figure S24. ${ }^{1} \mathrm{H}$ NMR spectrum $(800 \mathrm{MHz})$ of 5 in DMSO- $d_{6}$ 


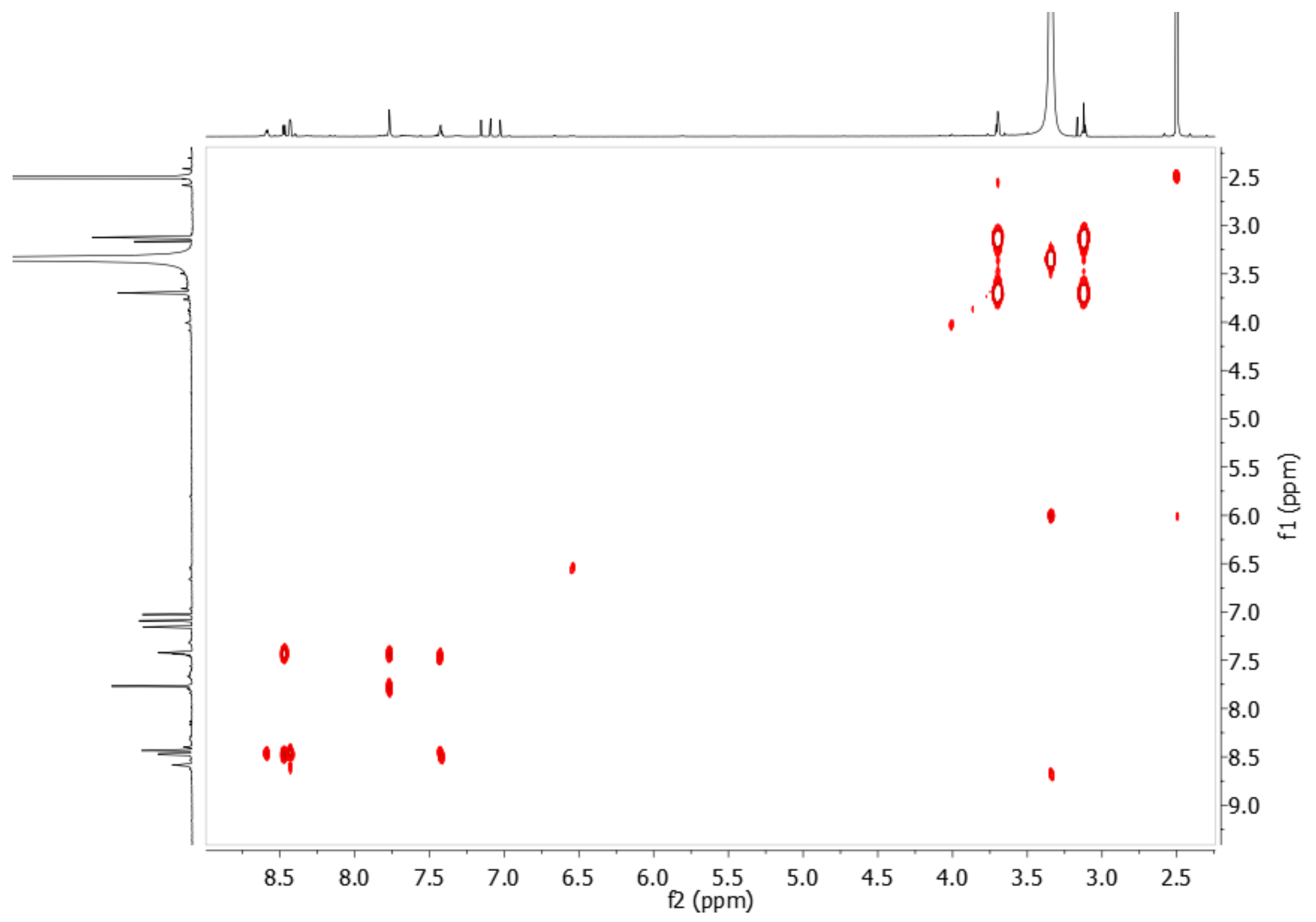

Figure S25. COSY NMR spectrum (800 MHz) of 5 in DMSO-d 6 


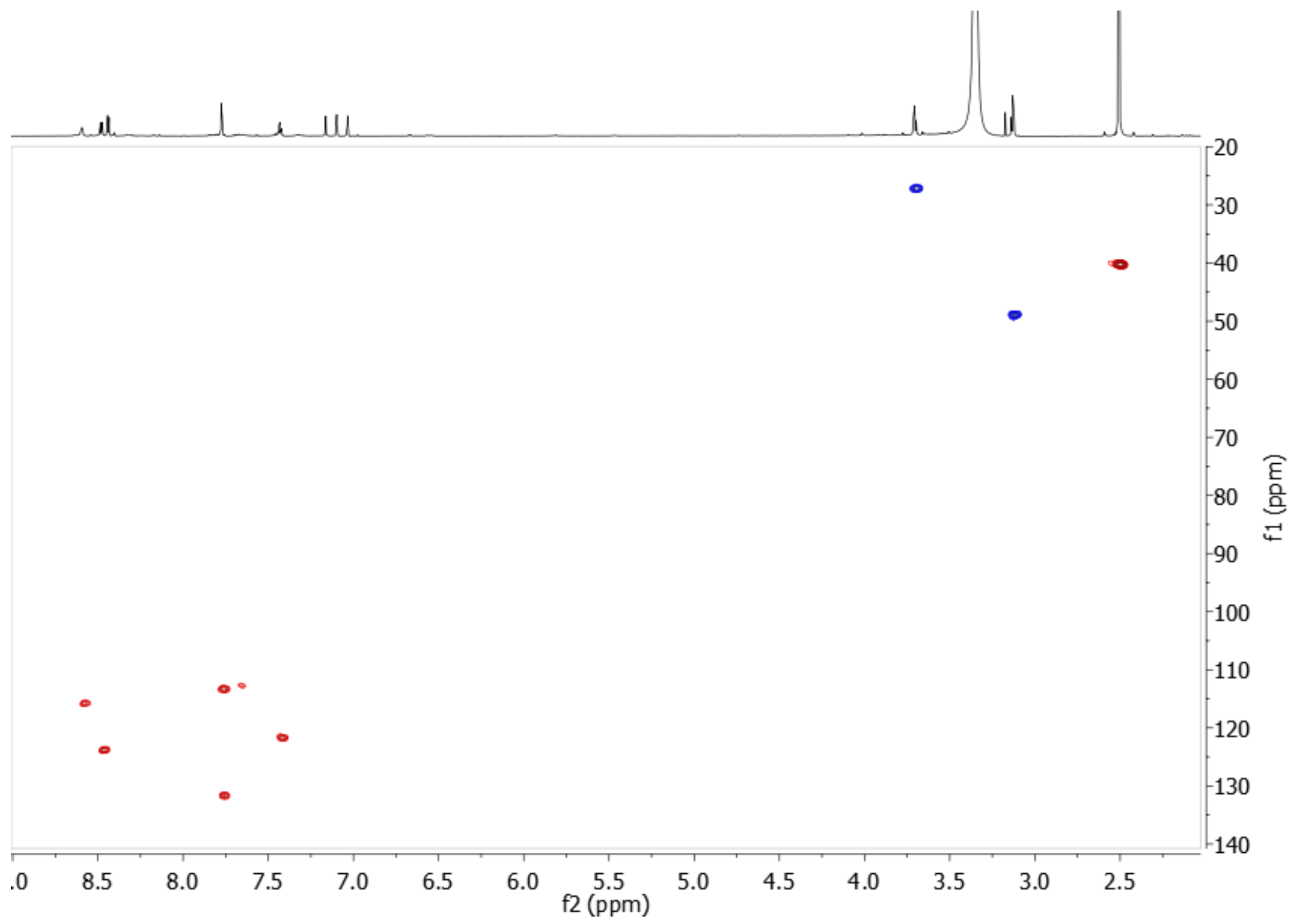

Figure S26. HSQC NMR spectrum (800 MHz) of 5 in DMSO- $d_{6}$ 


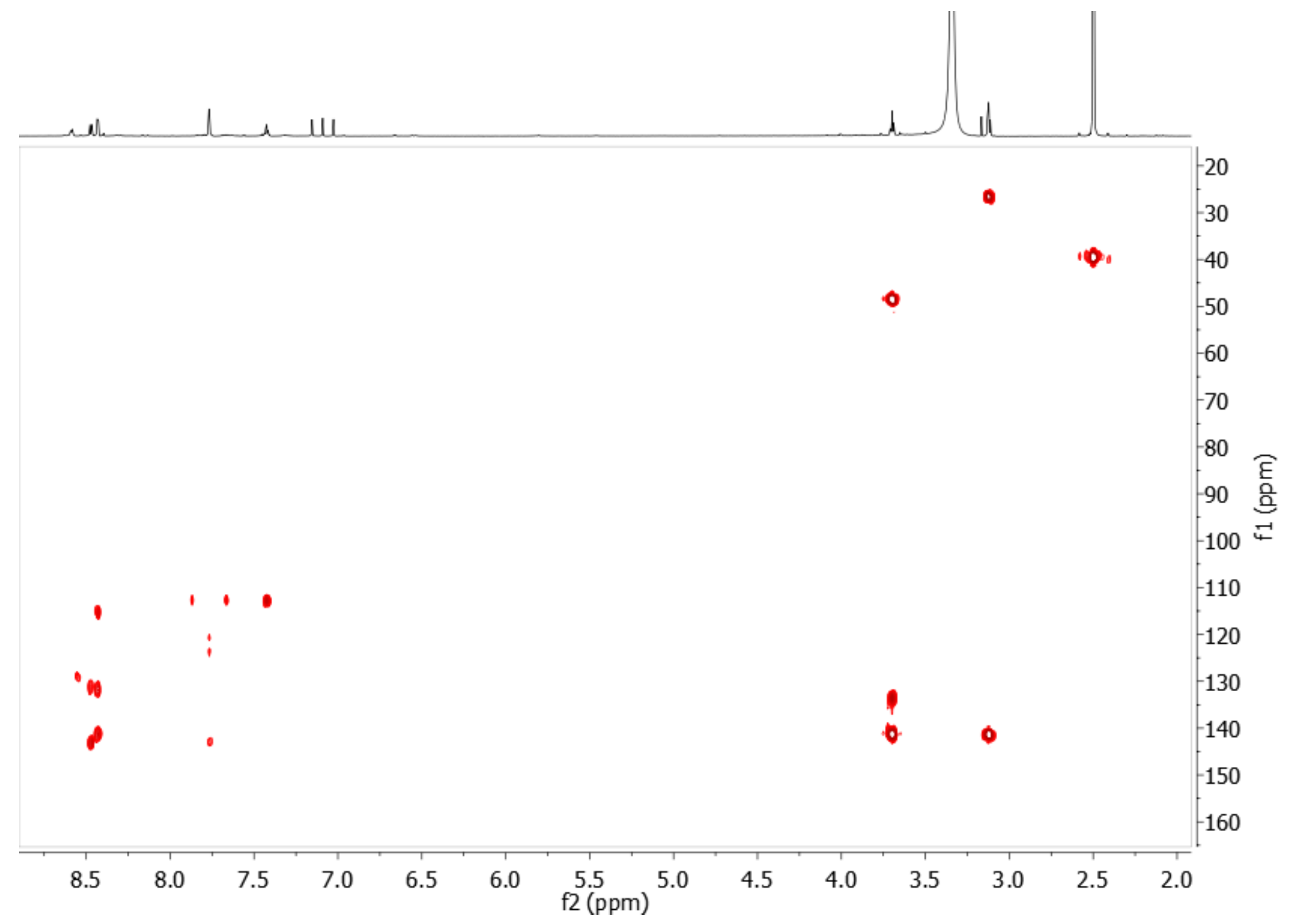

Figure S27. HMBC NMR spectrum (800 MHz) of 5 in DMSO- $d_{6}$ 



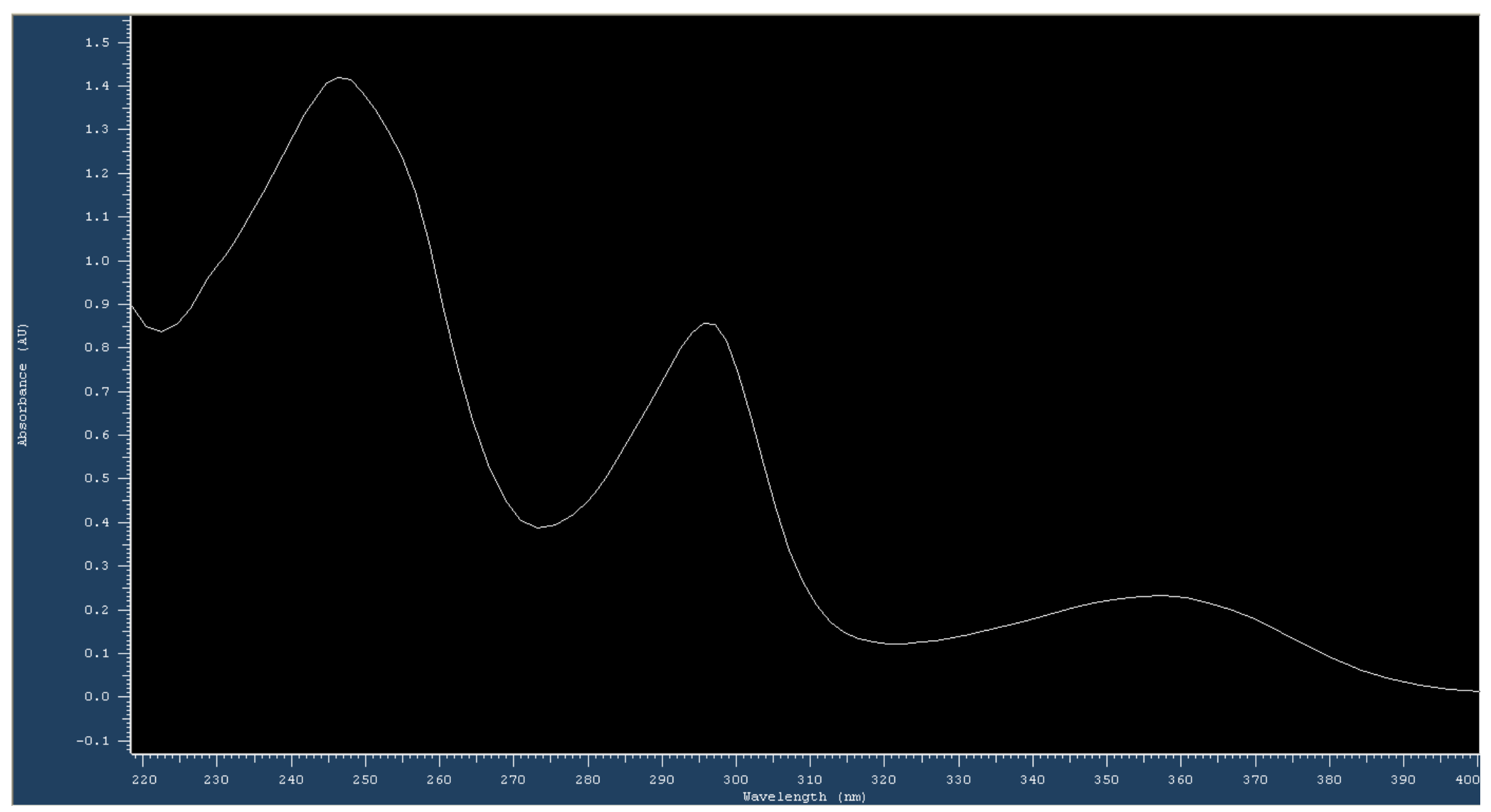

Figure S29. UV absorption spectrum of 4 (from HPLC separation) in $\mathrm{H}_{2} \mathrm{O} / \mathrm{MeOH}(0.1 \%$ TFA) 


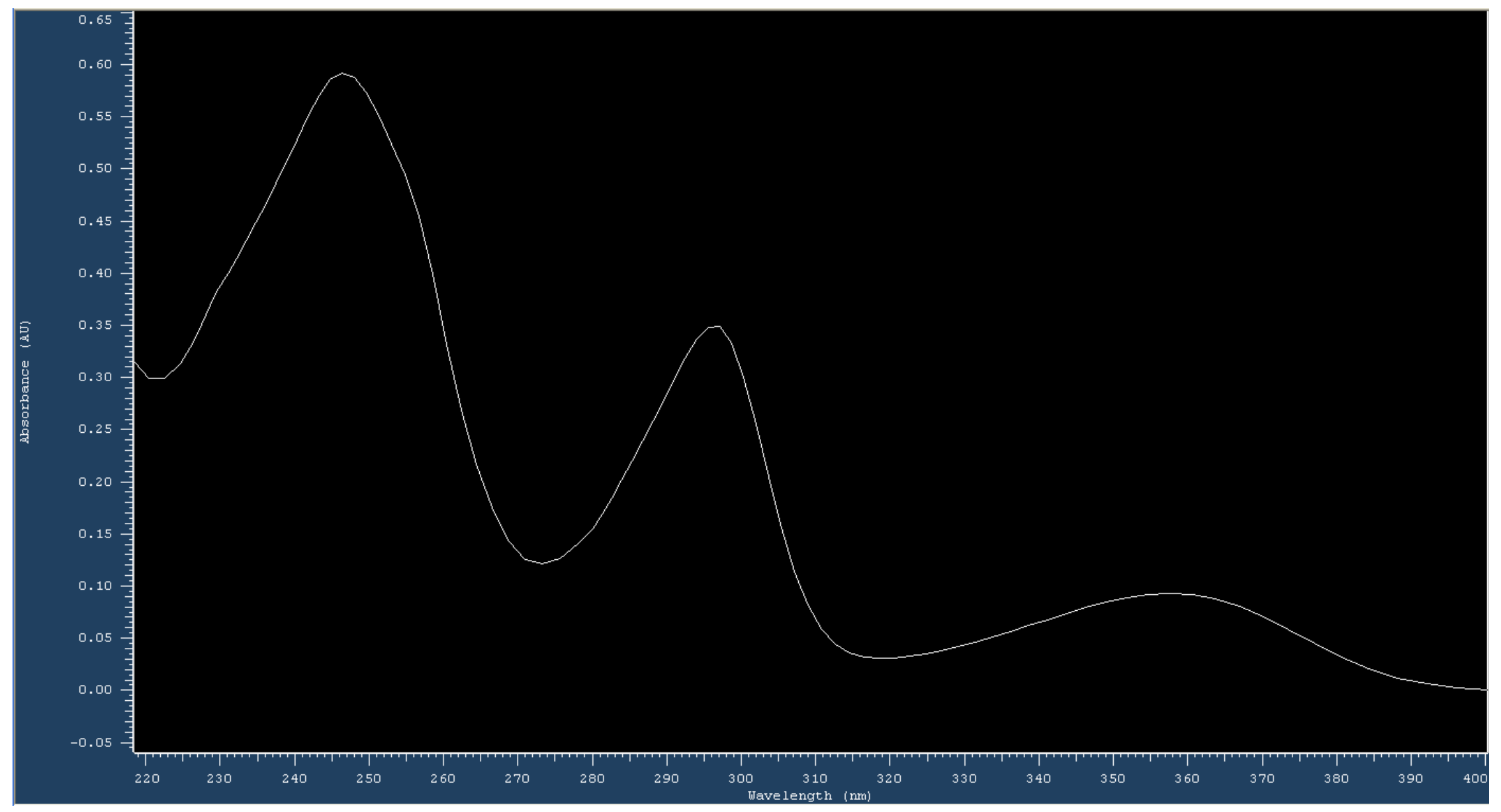

Figure S30. UV absorption spectrum of 5 (from HPLC separation) in $\mathrm{H}_{2} \mathrm{O} / \mathrm{MeOH}(0.1 \%$ TFA) 